\title{
SCience Hybrid Orbiter and Lunar Relay (SCHOLR) Architecture and Design
}

Kathryn K. Trase, Rachel A. Barch, Ryan E. Chaney, Rachel A. Coulter, Hui Gao, David P. Huynh, Nicholas A. Iaconis, Todd S. MacMillan, Gregory M. Pitner, and Devin T. Schwab

Glenn Research Center, Cleveland, Ohio 


\section{NASA STI Program . . . in Profile}

Since its founding, NASA has been dedicated to the advancement of aeronautics and space science. The NASA Scientific and Technical Information (STI) program plays a key part in helping NASA maintain this important role.

The NASA STI Program operates under the auspices of the Agency Chief Information Officer. It collects, organizes, provides for archiving, and disseminates NASA's STI. The NASA STI program provides access to the NASA Aeronautics and Space Database and its public interface, the NASA Technical Reports Server, thus providing one of the largest collections of aeronautical and space science STI in the world. Results are published in both non-NASA channels and by NASA in the NASA STI Report Series, which includes the following report types:

- TECHNICAL PUBLICATION. Reports of completed research or a major significant phase of research that present the results of NASA programs and include extensive data or theoretical analysis. Includes compilations of significant scientific and technical data and information deemed to be of continuing reference value. NASA counterpart of peer-reviewed formal professional papers but has less stringent limitations on manuscript length and extent of graphic presentations.

- TECHNICAL MEMORANDUM. Scientific and technical findings that are preliminary or of specialized interest, e.g., quick release reports, working papers, and bibliographies that contain minimal annotation. Does not contain extensive analysis.

- CONTRACTOR REPORT. Scientific and technical findings by NASA-sponsored contractors and grantees.
- CONFERENCE PUBLICATION. Collected papers from scientific and technical conferences, symposia, seminars, or other meetings sponsored or cosponsored by NASA.

- SPECIAL PUBLICATION. Scientific, technical, or historical information from NASA programs, projects, and missions, often concerned with subjects having substantial public interest.

- TECHNICAL TRANSLATION. Englishlanguage translations of foreign scientific and technical material pertinent to NASA's mission.

Specialized services also include creating custom thesauri, building customized databases, organizing and publishing research results.

For more information about the NASA STI program, see the following:

- Access the NASA STI program home page at http://www.sti.nasa.gov

- E-mail your question via the Internet to help@ sti.nasa.gov

- Fax your question to the NASA STI Help Desk at $443-757-5803$

- Telephone the NASA STI Help Desk at 443-757-5802

- Write to: NASA Center for AeroSpace Information (CASI) 7115 Standard Drive Hanover, MD 21076-1320 
NASA/TM-2011-216894

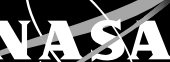

SCience Hybrid Orbiter and Lunar Relay (SCHOLR) Architecture and Design

Kathryn K. Trase, Rachel A. Barch, Ryan E. Chaney, Rachel A. Coulter, Hui Gao, David P. Huynh, Nicholas A. Iaconis, Todd S. MacMillan, Gregory M. Pitner, and Devin T. Schwab

Glenn Research Center, Cleveland, Ohio

Prepared for the

Space 2010 Conference and Exposition

sponsored by the American Institute of Aeronautics and Astronautics

Anaheim, California, August 30-September 2, 2010

National Aeronautics and

Space Administration

Glenn Research Center

Cleveland, Ohio 44135 


\section{Acknowledgments}

The authors would like to thank Dr. Kul Bhasin for his mentorship and passionate support of the SCHOLR Project. The authors also thank members of the Collaborative Modeling for Parametric Assessment of Space Systems (COMPASS) Team at NASA Glenn Research Center who provided much of the technical assistance essential to SCHOLR's design - specifically, Laura Burke, Kristen Bury, Anthony Colozza, James Fincannon, James Fittje, John Gyekenyesi, Jennifer Jordan, Geoffrey Landis, Michael Martini, Melissa McGuire, Steve Oleson, Thomas Packard, and Glenn Williams. The authors would like to recognize its SCaN mentors: Brian Barritt, Michael Fuentes, Bertsel Golden, and Eric Knoblock for their guidance throughout this project as well as Amber Gallihar and Katy Kafantaris for their editorial and graphic assistance. Lastly, the authors wish to thank NASA SCaN's Office of Policy and Strategic Communications for its financial support of this project.

Trade names and trademarks are used in this report for identification only. Their usage does not constitute an official endorsement, either expressed or implied, by the National Aeronautics and Space Administration.

Level of Review: This material has been technically reviewed by technical management.

Available from

NASA Center for Aerospace Information 7115 Standard Drive

Hanover, MD 21076-1320
National Technical Information Service 5301 Shawnee Road Alexandria, VA 22312 


\title{
SCience Hybrid Orbiter and Lunar Relay (SCHOLR) Architecture and Design
}

\author{
Kathryn K. Trase, Rachel A. Barch, ${ }^{*}$ Ryan E. Chaney, ${ }^{*}$ Rachel A. Coulter, ${ }^{*}$ Hui Gao, ${ }^{*}$ David P. Huynh, \\ Nicholas A. Iaconis, ${ }^{*}$ Todd S. MacMillan, ${ }^{*}$ Gregory M. Pitner, and Devin T. Schwab* \\ National Aeronautics and Space Administration \\ Glenn Research Center \\ Cleveland, Ohio 44135
}

\begin{abstract}
Considered both a stepping-stone to deep space and a key to unlocking the mysteries of planetary formation, the Moon offers a unique opportunity for scientific study. Robotic precursor missions are being developed to improve technology and enable new approaches to exploration. Robots, lunar landers, and satellites play significant roles in advancing science and technologies, offering close range and in-situ observations. Science and exploration data gathered from these nodes and a lunar science satellite is intended to support future human expeditions and facilitate future utilization of lunar resources. To attain a global view of lunar science, the nodes will be distributed over the lunar surface, including locations on the far side of the Moon. Given that nodes on the lunar far side do not have direct line-of-sight for Earth communications, the planned presence of such nodes creates the need for a lunar communications relay satellite. Since the communications relay capability would only be required for a small portion of the satellite's orbit, it may be possible to include communication relay components on a science spacecraft. Furthermore, an integrated satellite has the potential to reduce lunar surface mission costs. A SCience Hybrid Orbiter and Lunar Relay (SCHOLR) is proposed to accomplish scientific goals while also supporting the communications needs of landers on the far side of the Moon. User needs and design drivers for the system were derived from the anticipated needs of future robotic and lander missions. Based on these drivers and user requirements, accommodations for communications payload aboard a science spacecraft were developed. A team of interns identified and compared possible SCHOLR architectures. The final SCHOLR architecture was analyzed in terms of orbiter lifetime, lunar surface coverage, size, mass, power, and communications data rates. This paper presents the driving requirements, operational concept, and architecture views for SCHOLR within a lunar surface nodal network. Orbital and bidirectional link analysis, between lunar nodes, orbiter, and Earth, as well as a conceptual design for the spacecraft are also presented.
\end{abstract}

\subsection{Introduction}

As Earth's nearest celestial neighbor, the Moon is both a gateway to deep space exploration and a feasible platform from which to conduct scientific study of planetary formation. Although past lunar missions have provided great insight into the Moon's many mysteries, much science has yet to be conducted. Samples returned from Apollo and Luna missions, in addition to orbital data gathered from such satellite missions as Clementine and Lunar Prospector, provided a wealth of information on the lunar system. More recently, international orbiters and NASA's Lunar Reconnaissance Orbiter (LRO) are returning more complete and sophisticated data sets. However, even these missions leave questions to be answered and discoveries to be made about the Moon's origin and processes as well as the presence of water (Ref. 1).

Lunar surface missions are being proposed to help close the gaps in the current understanding of the Moon and planetary processes in general. These landers and robots will be deployed across the near and

\footnotetext{
*Summer interns supported by the Lewis' Educational and Research Collaborative Internship Program (LERCIP), a collaborative undertaking by the NASA Glenn Research Center and the Ohio Aerospace Institute
} 
far sides of the Moon to better obtain a global perspective of the Moon's environment and processes. For assets on the far side, communication with Earth is impossible, and for many locations on the near side, communication can be difficult. Including a powerful communications system or planning for a partner lunar relay satellite would quickly increase mission costs. A SCience Hybrid Obiter and Lunar Relay (SCHOLR) is proposed to provide communications capabilities to these landers as they explore the lunar surface at a reduced net cost. SCHOLR aims to serve as a data relay from the lunar surface to Earth in order to enable exploration of the lunar far side while additionally capturing scientific data on the lunar North Pole.

SCHOLR would expand our knowledge of the Moon's environment by characterizing water content, surface composition, variety and distribution of lunar rocks, and crust thickness at the lunar North Pole. Whether preparing for prolonged human stay, mining lunar resources, or using the Moon as a technology demonstration platform, a more complete understanding of the surface will aid mission planners in selecting the best approach to produce a hardy system and emplace it in the most scientifically advantageous location on the Moon. Study of the lunar crust would also provide insight into planetary evolution and advance our knowledge of how the Earth was formed (Ref. 1).

As a secondary goal, SCHOLR may become a tool for creating excitement for space exploration among students. Inspired by man's presence on the Moon during the Apollo era, the previous generation of young scientists and engineers were motivated by a sense of exploration and discovery. Presently, the fervor and excitement for space exploration has faded in the more than $40 \mathrm{yr}$ since the Apollo missions, leaving today's young scientists and engineers searching for a renewed source of inspiration and purpose. Given the immense advancement of current technologies and capabilities since the 1960s, the space programs of this era are poised to provide the new generation with limitless possibilities. Small lunar landers and robots could soon be developed by commercial institutions or university students and operated by grade school science classes.

This paper presents SCHOLR's mission context, innovations, and science and communication objectives in Section 2.0. Section 3.0 discusses high level mission requirements, system architecture, and concept of operations. SCHOLR's science and communication payloads and orbit are presented in Section 4.0. The subsystems integration process is discussed in Section 5.0, and a conceptual discussion of the spacecraft subsystems follows: Structures; Environmental Control; Guidance, Navigation and Control (GN\&C); Power; Command and Data Handling (C\&DH); and Communications.

\subsection{SCHOLR Mission Context and Objectives}

\subsection{Mission Context}

Both SCHOLR and surface assets would collectively contribute to the advancement of lunar science as well as general space technology. Lunar science data gathered from these sources would be used to demonstrate new technologies and serve to maintain scientific momentum as new discoveries are made that may be applied throughout NASA and the global community. The Object-Process Methodology (Ref. 2) was used to develop the mission context in terms of the users, mission objectives, and the role of SCHOLR. The main context diagram illustrating the ultimate users of the data returned by SCHOLR and lunar surface assets are illustrated in Figure 1.

\subsection{SCHOLR Innovations and State-of-the-Art}

\subsubsection{Hybrid Satellites}

Concepts of "hybrid" satellites in a general sense are not new. Currently, the Canadian Space Agency has plans to launch a hybrid Earth satellite in 2011 (Ref. 3) with a primary science mission and secondary communications demonstration (Ref. 4). NASA's Mars Reconnaissance Orbiter, launched in 2005, has taken scientific data of the Martian surface while also serving as a communications link for rovers back to 


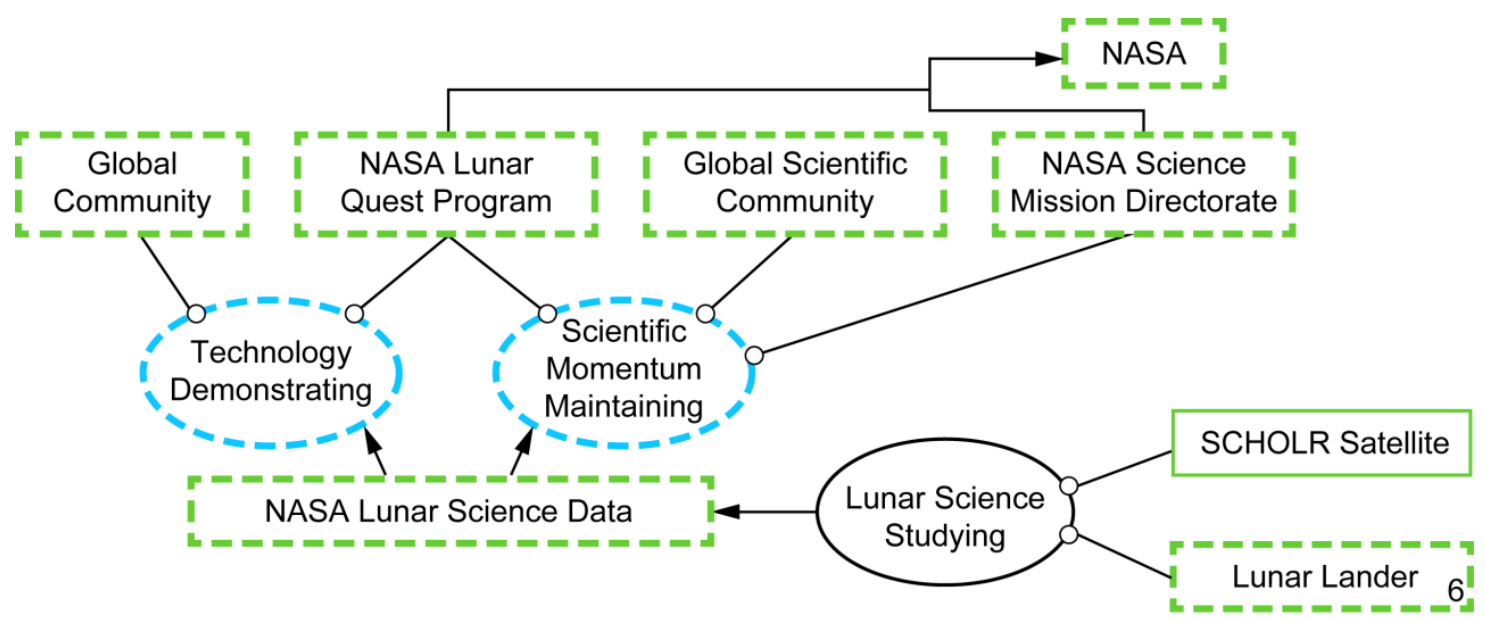

Figure 1.-SCHOLR and Lander Context Diagram. Both SCHOLR and lunar landers are instrumental in the process of studying the Moon. The data gathered by both elements would contribute to technology development and general scientific understanding. NASA, the scientific community, and the public would all benefit from this new knowledge.

Earth (Ref. 5). Design teams have investigated constellations of lunar satellites to provide continuous communications coverage for the lunar surface (Refs. 6 and 7), but these designs have not incorporated the capability to collect scientific data on the spacecrafts.

SCHOLR would be the first lunar science satellite to provide communications relay to assets on the lunar surface. The hybrid nature of SCHOLR would permit scientific observation of the North Pole when communications relaying is infeasible. Conversely, SCHOLR would serve as a data relay when practical science cannot be conducted.

\subsubsection{Science Instruments}

The Science Instrument Payload (SIP) includes an Active Infrared Spectrometer (AIRS) that has never flown in space. This instrument would provide new insights into the water content of the Moon that previous spectrometers, passive or otherwise, have not been able to produce due to inherent limitations in the method of observation.

The optical communications technology demonstration would be a follow-on to the laser communication demonstration on the Lunar Atmosphere and Dust Environment Explorer (LADEE), expected to launch in 2013 (Ref. 8).

\subsubsection{Mission Cost}

By effectively providing the capability of two satellites within one orbiter, SCHOLR seeks to reduce mission costs. Although a noble quest by itself, scientific exploration is costly and careful considerations must be made to ensure a maximum return on investment. SCHOLR's lifecycle cost is estimated to be between $\$ 600$ to $\$ 700$ million, including the cost of launch and ground operations for the nominal $3 \mathrm{yr}$ mission. SCHOLR's relay capabilities may serve to reduce mission costs for future landers and rovers it would support by reducing the surface assets' communications constraints and landing site restrictions.

\subsection{Science Objectives}

SCHOLR's science goals and objectives were adapted from the priorities outlined in the 2007 study by the National Research Council, entitled "Scientific Context for Exploration of the Moon (SCEM)" (Ref. 1). SCEM sought to provide scientific guidance for future lunar activities by prioritizing lunar science goals. These science objectives include gathering additional data to answer questions of: lunar 
bombardment history, polar environment, and volcanism; structure and composition; planetary, impact, and regolith processes; and permanently shadowed craters. SCEM gave consideration to the intended measurements by recent lunar orbiter missions, Chang'e-1, SELENE, Chandrayaan-1, and LRO, and new objectives were developed under the assumption that each mission would be successfully completed. Given the overall success of these programs, the goals outlined in the study were selected to become SCHOLR's mission goals. SCHOLR's science goals and objectives, as adapted from SCEM, are listed in order of importance in Table 1.

TABLE 1.-SCHOLR SCIENCE GOALS AND MEASUREMENT OBJECTIVES

\begin{tabular}{|l|l|}
\hline \multicolumn{1}{|c|}{ Science goal } & \multicolumn{1}{c|}{ Science measurement objective } \\
\hline $\begin{array}{l}\text { Determine the extent of water on the lunar surface and in the } \\
\text { subsurface. }\end{array}$ & $\begin{array}{l}\text { Provide high resolution measurements of hydroxyl groups } \\
\text { and identify water ice deposits. }\end{array}$ \\
\hline Determine the age and chronology of lunar craters. & Provide higher-resolution images of lunar terrains. \\
\hline $\begin{array}{l}\text { Determine the compositional state and compositional } \\
\text { distribution of volatile components in lunar polar regions. }\end{array}$ & $\begin{array}{l}\text { Provide high-spatial resolution distribution of volatiles on } \\
\text { and in the regolith. }\end{array}$ \\
\hline Determine the extent and composition of crust, KREEP layer. & $\begin{array}{l}\text { Provide higher-resolution geophysical measurements of } \\
\text { representative regions. }\end{array}$ \\
\hline Determine the thickness of lunar crust and its variability. & Provide high-resolution gravity measurements. \\
\hline Determine the variety, age, and distribution of lunar rock. & $\begin{array}{l}\text { Provide higher-resolution global and regional mineralogic } \\
\text { and geochemical maps. }\end{array}$ \\
\hline
\end{tabular}

\subsection{Communications Relay Objectives}

The Lunar Communications Payload (LCP) in conjunction with the SIP would allow SCHOLR to fulfill its innovative role as a hybrid science and communications satellite. Since the lunar poles and lunar far side have minimal to no direct access to Earth, it is impossible to effectively communicate with surface assets in these areas of the Moon without a lunar relay. The LCP would provide surface assets at the lunar South Pole and far side with communications access to Earth, thus enabling surface missions to take place in low access, high scientific gain areas. To provide an effective means of communicating with surface assets in these areas, the LCP must support the large volume of science data generated by the surface assets, as well as low data rates for real-time command and monitoring of the assets. The LCP would also provide these capabilities to sites that do have direct to Earth (DTE) access to ease the communications burden (in terms of size, weight, and power) on those assets. By providing relay access to Earth at high rates, scientists could collect surface measurements from sites that have been impractical in the past due to limited DTE access. This data, when combined with in-orbit measurements, would give scientists a more accurate and global picture of the Moon.

\subsection{High Level Mission Requirements and Architecture}

High-level mission requirements were derived from NASA's lunar exploration objectives and are discussed in Section 3.1. SCHOLR's system architecture was developed following Department of Defense Architecture Framework and can be found in Section 3.2. From these requirements and architecture, SCHOLR's concept of operations was created and is presented in Section 3.3.

\subsection{High-Level Requirements}

Considering both the scientific and communications objectives of SCHOLR, high-level mission requirements were developed to ensure those goals would be realized. The high-level mission requirements include:

- SCHOLR shall collect lunar scientific data to fill knowledge gaps of the lunar North Pole at both the surface and subsurface levels. 
- SCHOLR shall provide the capability to relay science data and real time commands between the Mission Operations Center (MOC) and the lunar surface mission.

- SCHOLR shall characterize exploration sites and transportation routes for future lunar surface missions.

- SCHOLR shall provide the capability to perform communications technology demonstrations.

- SCHOLR shall demonstrate the communications relay capability on the lunar far side below the lunar equator.

From these high-level requirements, the Science Instrument Payload (SIP) was selected and mission orbit and concept of operations were determined.

\subsection{System Architecture}

SCHOLR's system architecture was derived based on the high-level requirements with the Department of Defense Architecture Framework (Ref. 9). In the system view, SCHOLR would perform scientific observation of the lunar surface $100 \mathrm{~km}$ above the North Pole when communication with surface assets would be impractical. While orbiting $5798 \mathrm{~km}$ over the South Pole, SCHOLR would function as a data relay for surface assets within view when scientific measurement would be infeasible. SCHOLR's system views can be seen in Figure 2.

In the operational view, science data gathered by surface assets would be received by SCHOLR and transmitted to Earth through future 18-m dish ground stations at the Deep Space Network (DSN) sites, a component of the Space Communications and Navigation (SCaN) network. Science data gathered by SCHOLR would also be sent to Earth through the same network. SCaN networks would send raw science data to the Science Data Processing Center, where the data could be prepared for release to the public. Both the science community and international entities would make use of the data generated by the surface assets and SCHOLR. Telemetry data would also be received by SCaN ground stations and forwarded to SCHOLR's MOC. The MOC would then uplink new commands and telemetry data through SCaN networks to SCHOLR to continue the mission. Figure 3 depicts the operational view of SCHOLR.
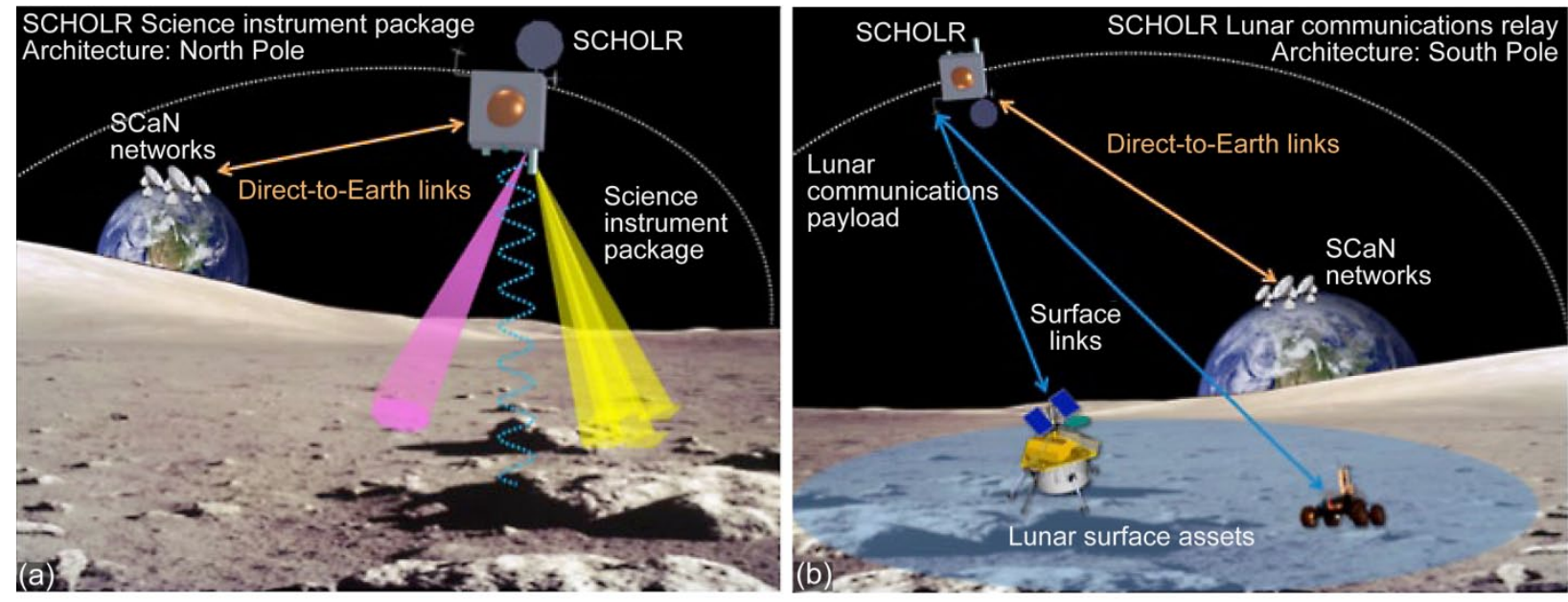

Figure 2.- SCHOLR system views. (a) Depicts SCHOLR taking scientific measurement of the lunar surface at the North Pole while also communicating back to Earth. (b) Depicts the communications payload aboard SCHOLR relaying data from lunar surface assets (Ref. 10) in the southern hemisphere back to Earth. Only a single asset would be serviced at a time. Scientific observation is not feasible during this portion of the orbit. 


\subsection{Mission Concept of Operations}

SCHOLR would launch in 2016 from NASA's Kennedy Space Center aboard a Falcon 9 launch vehicle. Following launch, SCHOLR would begin a trans-lunar injection after separation from the Falcon 9 vehicle. A series of course correction burns would be performed to ensure SCHOLR would reach the Moon's gravitational field. Arriving at the Moon four days after launch, SCHOLR would perform several capture burns to enter a highly elliptical polar orbit with an $8 \mathrm{hr}$ period, requiring approximately $500 \mathrm{~m} / \mathrm{s}$ delta-V. SCHOLR would remain in this orbit for a nominal $3 \mathrm{yr}$ mission.

Upon reaching lunar orbit, SCHOLR would deploy the radar sounder boom and verify the subsystems are functioning properly. SCHOLR would gather scientific data as it passes over relevant sites at $100 \mathrm{~km}$ above the lunar North Pole, while additionally continuing to communicate with the Earth. During the pass $5798 \mathrm{~km}$ above the lunar South Pole, SCHOLR would relay its own data, as well as data collected by surface assets in the southern hemisphere, back to Earth at 200 Mbps. SCHOLR's mission architecture is represented in the system views seen in Figures 2(a) and (b). SCHOLR would periodically perform orbital maintenance burns of approximately $400 \mathrm{~m} / \mathrm{s}$ delta- $\mathrm{V}$ to counteract the influence of the Moon's uneven gravitational field.

When in the shadow of the Moon, SCHOLR would enter into a power-save mode, where functionality of the SIP and other spacecraft components are limited to conserve the battery. These periods of shadow are expected to occur several times throughout the mission. Upon re-entry into the sunlight, SCHOLR would produce power using the solar array.

Upon successful completion of the nominal mission, SCHOLR could perform an orbit maneuver to reach a frozen elliptical orbit for a 4 yr extended mission. SCHOLR would remain in this low maintenance orbit through the end of the mission. SCHOLR would primarily function as a communications relay for surface assets during this extended mission.

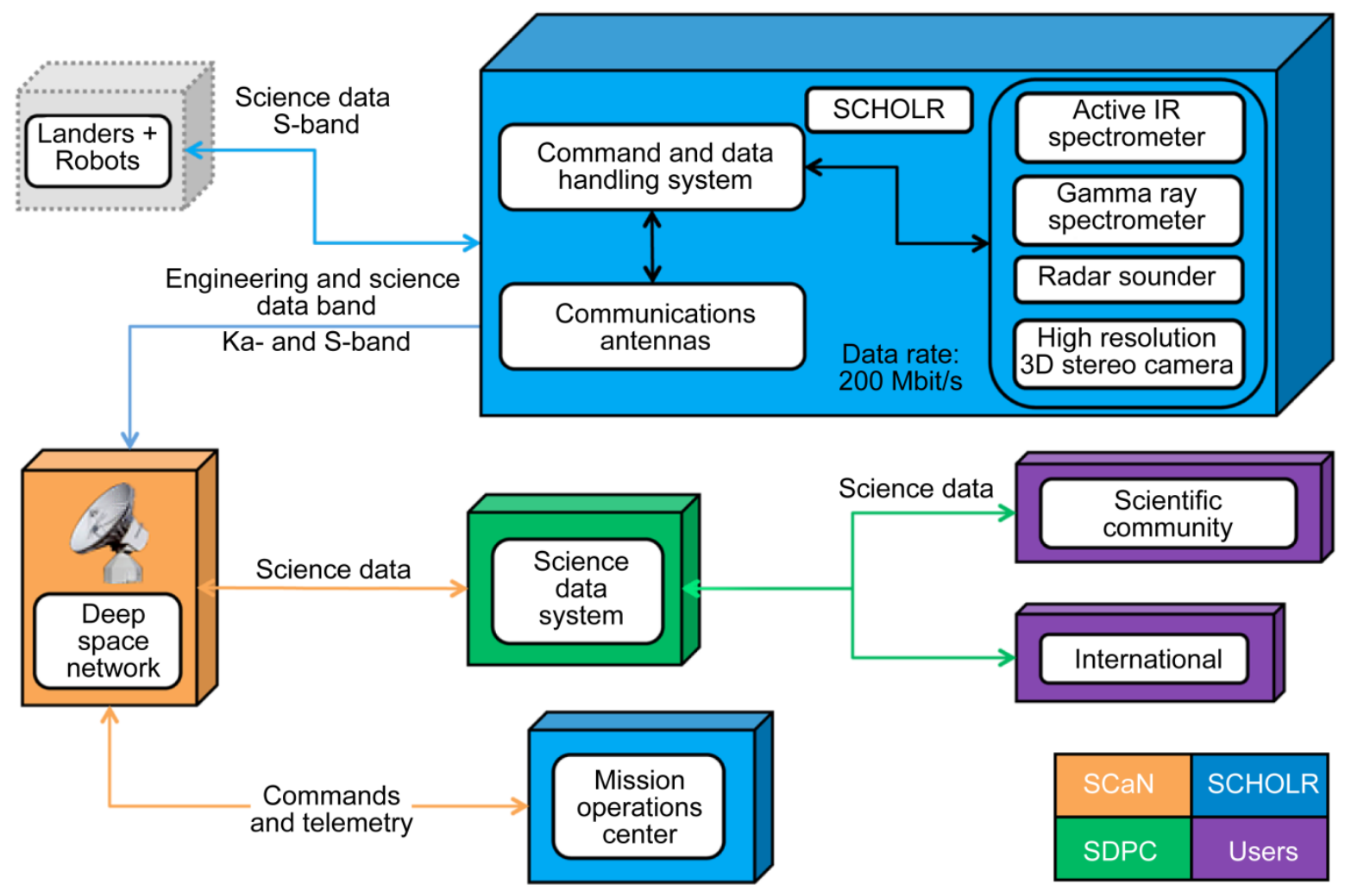

Figure 3.-SCHOLR operational view. 


\subsection{SCHOLR Payloads and Orbit}

Following development of SCHOLR's mission requirements and architecture, the science instrument and communications relay payloads were determined. The instrument requirements and payload selection is presented in Section 4.1. Section 4.2 discusses the communications relay payload. To best support the needs of both payloads, SCHOLR's orbit was optimized. The results of this analysis are presented in Section 4.3.

\subsection{Science Instrument Payload}

High-level science requirements were developed to accomplish the mission goals and objectives recommended in SCEM while additionally supporting the high-level mission requirements. SCHOLR's SIP was selected to best support these science mission requirements at the lowest cost and weight. The SIP includes a stereo camera, Active Infrared Spectrometer (AIRS), Gamma Ray Spectrometer (GRS), and a radar sounder. An optical communications technology demonstration would also be flown with the SIP. The first priority of SCHOLR is to investigate the presence of water ice at the lunar North Pole. By flying the SIP, our understanding of the Moon would be advanced through SCHOLR's investigation of the presence of the hydroxyl functional group, hydrogen, and water ice. Table 2 summarizes SCHOLR's science requirements and denotes the instruments that contribute to satisfying those requirements.

TABLE 2.-SCHOLR SCIENCE REQUIREMENTS AND INSTRUMENTS

\begin{tabular}{|c|c|c|c|c|}
\hline Science measurement requirement & $\begin{array}{l}\text { Stereo } \\
\text { camera }\end{array}$ & $\begin{array}{c}\text { Active IR } \\
\text { spectrometer }\end{array}$ & $\begin{array}{c}\text { Gamma ray } \\
\text { spectrometer }\end{array}$ & $\begin{array}{c}\text { Radar } \\
\text { sounder }\end{array}$ \\
\hline Identify hydroxyl functional groups at the lunar North Pole & & $\bullet$ & & \\
\hline Identify water ice deposits at the lunar North Pole & & $\bullet$ & $\bullet$ & $\bullet$ \\
\hline $\begin{array}{l}\text { Obtain stereo imaging of North Pole lunar surfaces at multiple } \\
\text { spatial resolutions and at multiple illumination angles }\end{array}$ & $\bullet$ & & & \\
\hline $\begin{array}{l}\text { Characterize the distribution of volatiles on and in the regolith at } \\
\text { the lunar North Pole }\end{array}$ & & $\bullet$ & $\bullet$ & \\
\hline Map lunar mineralogy and geochemistry in the North Pole & & - & $\bullet$ & $\bullet$ \\
\hline Provide high-resolution gravity measurements & & $\bullet$ & $\bullet$ & $\bullet$ \\
\hline
\end{tabular}

\subsubsection{Stereo Camera}

The SCHOLR High Resolution Stereo Camera's measurement objective is to provide targeted crater counts as well as reference photography for data from the other sensors in the SIP. Borrowing significantly from the heritage of the Lunar Reconnaissance Orbiter Camera (LROC), this camera package would provide detailed images in three dimensions of areas of interest to the science community. Two narrow angle cameras taking overlapping pictures as the spacecraft moves through orbit would allow for three dimensional terrain maps to be constructed. A wide-angle camera would provide contextual images for the science instruments.

\subsubsection{Active Infrared Spectrometer (AIRS)}

The SCHOLR AIRS would use infrared lasers to characterize the presence of the hydroxyl functional group in areas without illumination on the Moon, such as permanently shadowed craters. AIRS aims to fill in where the Moon Mineralogy Mapper flown on Chandrayaan-1 left off (Ref. 11). In much the same way as the Lunar Orbiter Laser Altimeter (LOLA) measured surface roughness; the AIRS would use three lasers in the mid-infrared spectrum, at 2.7, 2.8, and 3.1 $\mu \mathrm{m}$, to determine the presence of $\mathrm{OH}$ via absorption: hydroxyl concentration would be determined by the intensity of the laser pulses reflected by the lunar surface.

\subsubsection{Gamma Ray Spectrometer (GRS)}

The SCHOLR GRS would create high-resolution maps of the chemical composition of the lunar surface. It would detect characteristic gamma rays from lunar aluminum, calcium, hydrogen, iron, 
magnesium, oxygen, potassium, silicon, thorium, titanium, and uranium. These measurements would contribute to our knowledge of the lunar crust composition and planetary formation processes.

SCHOLR's GRS aims to improve upon the energy resolution and precision of the germanium gamma-ray spectrometer aboard Japan's SELENE spacecraft (Ref. 12).

\subsubsection{Radar Sounder}

The SCHOLR radar sounder would investigate lunar subsurface ice with two 15-m dipole antennas. The radar sounder would emit radio waves at $5 \mathrm{MHz}$, a frequency able to penetrate the lunar surface as far as $25 \mathrm{~km}$. A circularly polarized radar reflection would indicate the presence of water ice. Additionally, data from this instrument could be combined with data previously acquired from the LOLA (Ref. 13) to determine the thickness and subsurface structure of the Moon's crust.

\subsubsection{Optical Communications Technology Demonstration}

A portion of SCHOLR's mass and power budgets has been allotted to accommodate an optical communications technology demonstration. Compared to traditional RF communication, optical can deliver higher data rates, up to 1 Gbps, at a lower mass and power (Ref. 14). Optical communication technology is capable of communicating at high bandwidth and at distances up to 40 astronomical units. These communication links could enable the next generation of exploration missions. The Lunar Laser Communication Demonstration aboard LADEE, to be launched in 2013, is being developed to demonstrate an optical 622 Mbps downlink, and up to 20 Mbps uplink (Ref. 15). The NASA Jet Propulsion Laboratory (JPL) is also developing optical communication technology for missions to the Moon and outer planets (Ref. 14). Given that JPL's technology is not being developed to fly a particular mission, SCHOLR could be available to demonstrate this system and help further this revolutionary communication technology.

\subsection{Communications Payload}

\subsubsection{Link Requirements}

In order to provide relay capabilities as functional as DTE access, it was determined that the LCP should provide three different links to the surface. One link should receive scientific data at a high rate. The other two links would provide real-time Tracking, Telemetry, and Command (TT\&C) at low data rates. All three of these links must minimize the number of errors in the transmission in order to ensure the data is of high quality and that commands can be processed correctly. To satisfy these requirements, it was determined that all three links must exhibit a bit error rate (BER) of $10^{-8}$ or less, with a link margin of $3 \mathrm{~dB}$ or more. The low BER reduces the probability that an error will occur during the transmission, and the link margin allows for unexpected and uncalculated losses in the communications system (Ref. 6).

\subsubsection{Surface Asset Assumptions}

It is important to have reasonable assumptions about the capabilities of the surface assets' communications systems in order to appropriately design the LCP and the parameters of each link. To make these assumptions, various other lunar communication packages, both conceptual and flown, were researched (Refs. 16 to 18). The assumptions based on that research are summarized in Table 3.

TABLE 3.-SURFACE ASSET ASSUMPTIONS

\begin{tabular}{|c|}
\hline Assumed value \\
\hline .........................High gain parabolic \\
\hline 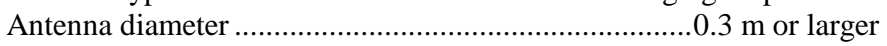 \\
\hline Transmit power \\
\hline Receiver system noise temperature ...................................... $290 \mathrm{~K}$ or less \\
\hline 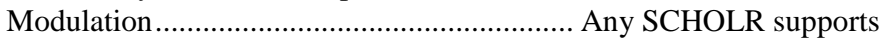 \\
\hline 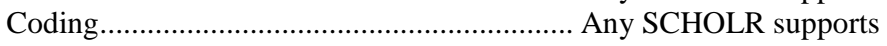 \\
\hline
\end{tabular}




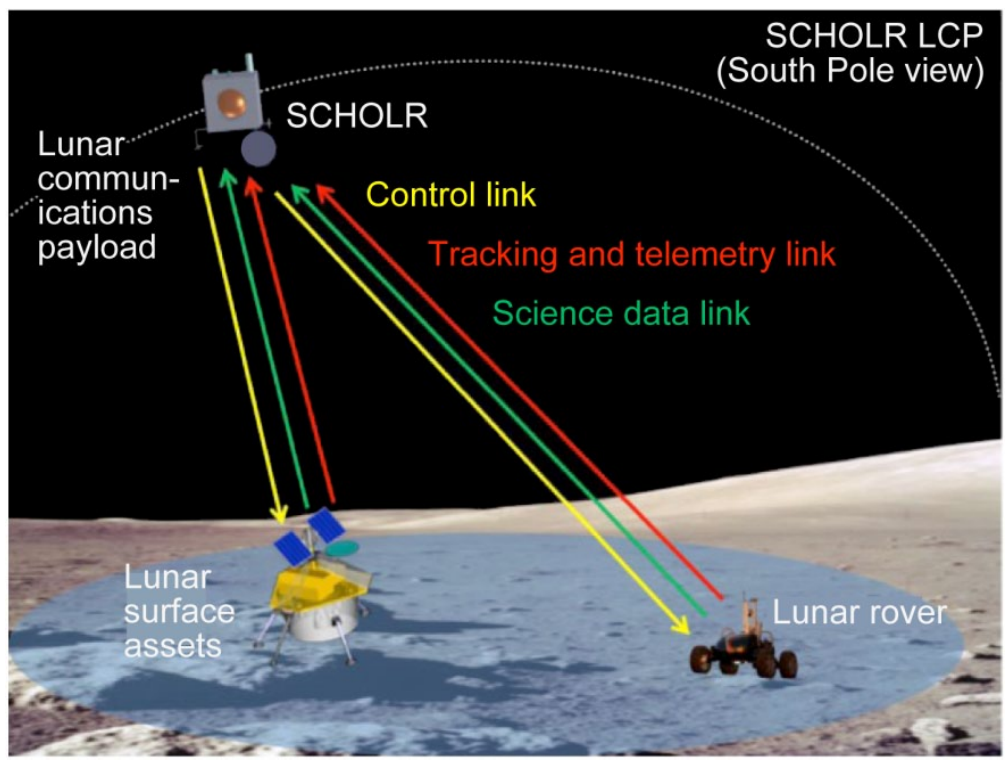

Figure 4.-LCP communications architecture. Yellow represents the command link; Red, telemetry and tracking link; Green, high data rate science link.

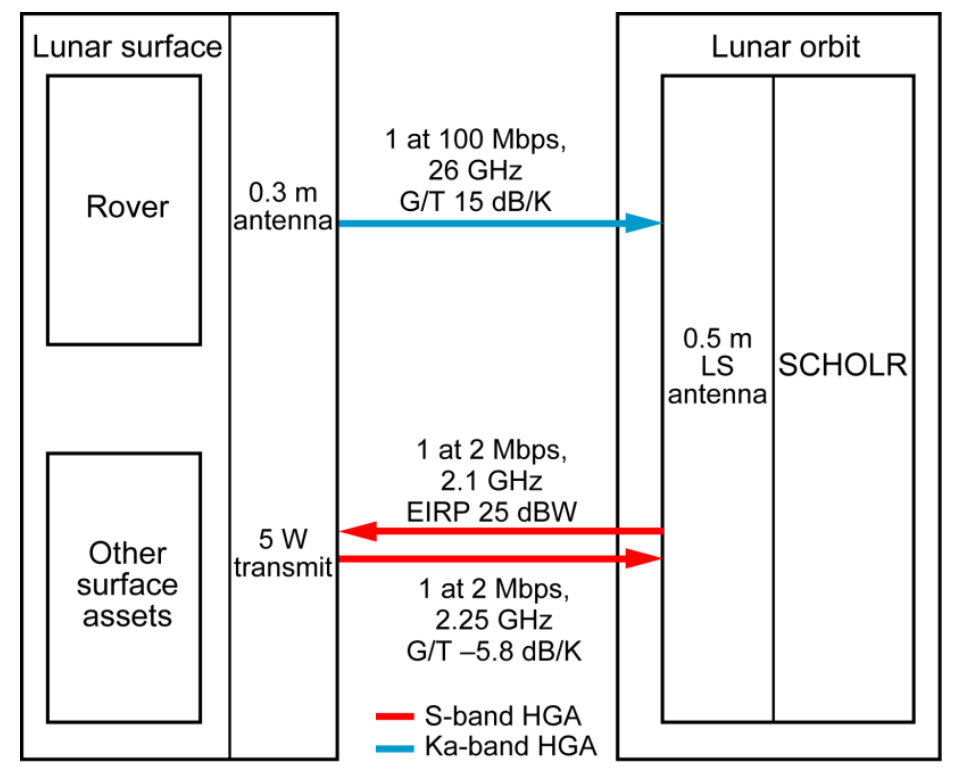

Figure 5._Link parameter summary for LCP.

The data rates for each link were determined based on the expected types of instruments on the lunar surface assets and the amount of data these instruments would generate. It was determined that the high data rate link should support rates up to $100 \mathrm{Mbps}$, accommodating both instruments that generate large volumes of data quickly and instruments that generate small volumes of data but store a large amount. Low data rate TT\&C links were determined to require 2 Mbps to support real-time monitoring and control. S-band was found to be the best option for TT\&C links and Ka-band would support the high data rate link. S-band is well developed and would allow maximum usage of commercial off the shelf (COTS) packages, minimizing cost and facilitating greater interoperability between the LCP and the lunar surface assets. Ka-band was chosen for the high data rate link because it has been proven to support data rates up to $100 \mathrm{Mbps}$ by the $\mathrm{LRO}^{16}$. Figure 4 illustrates the communications architecture on the lunar surface. A summary of the parameters for each link is shown in Figure 5. 


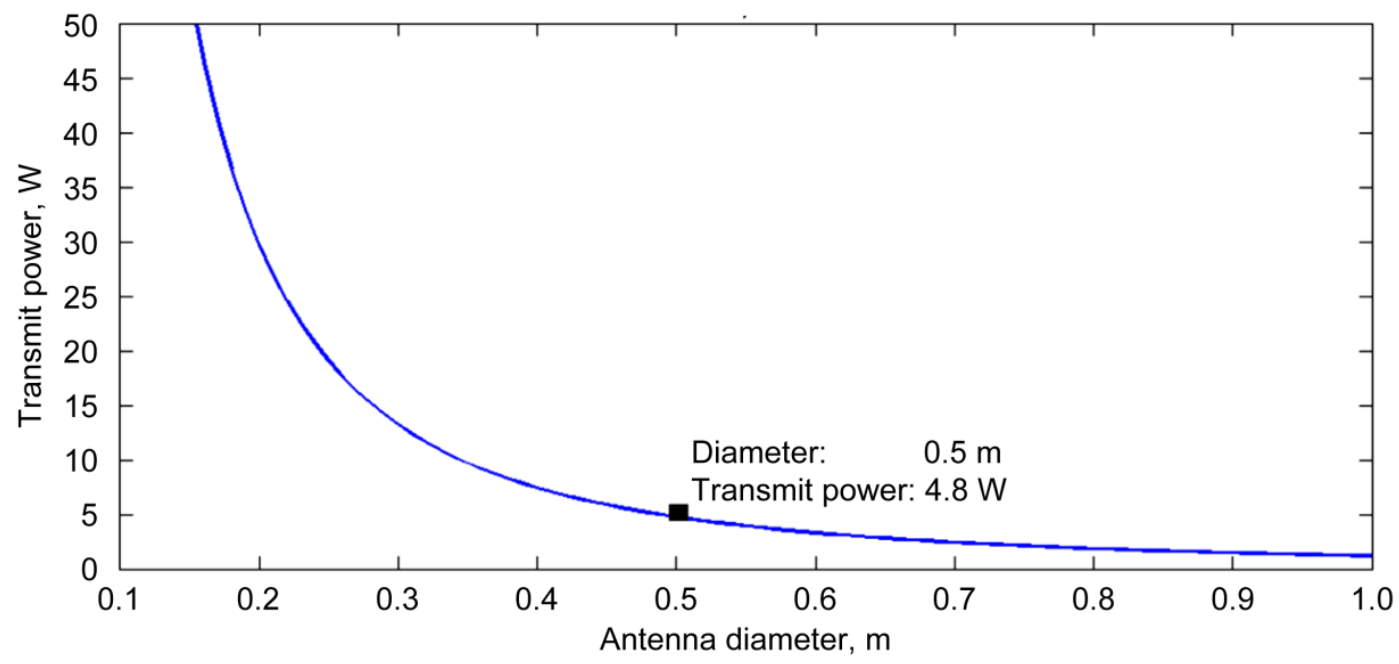

Figure 6.-Transmit power versus antenna diameter. EIRP of $25 \mathrm{dBW}$ and frequency of $2.1 \mathrm{GHz}$.

\subsubsection{Link Design}

Using these parameters, a model of the scenario was created using an analysis software tool called the Satellite Tool Kit (STK) (Ref. 19). Using STK, link properties were explored and data was collected for the different options available in the LCP's design. Quadrature phase shift keying (QPSK) modulation with low-density parity-check (LDPC) coding was determined to be the best combination of modulation and coding because it had the lowest required signal-to-noise ratio $\left(\mathrm{E}_{\mathrm{b}} / \mathrm{N}_{0}\right)$ necessary to meet the BER requirement (Ref. 20).

The Equivalent Isotropic Radiated Power (EIRP) necessary to close the command link was first determined in order to minimize the number of unknown factors while designing the LCP. To determine the necessary EIRP, access time was used as a figure of merit because it would indicate the amount of time the link was closed. It was assumed that more access time was better because it would allow for more surface assets to be serviced and each asset to be serviced longer. The transmit power and antenna diameter were sized using the determined EIRP of $25 \mathrm{dBW}$. A plot of the relationship between transmit power and antenna diameter, assuming 55 percent antenna efficiency, is shown in Figure 6 (Ref. 21). Based on this relationship it was determined that a $0.5 \mathrm{~m}$ antenna with $4.8 \mathrm{~W}$ of transmit power would be able to meet the requirements for the command link while remaining within constraints for power, size, and mass.

It was then verified that a $0.5 \mathrm{~m}$ antenna required an acceptable system noise temperature to meet the required gain over system noise temperature, G/T. A plot of system noise temperature vs. antenna diameter for both links is shown in Figure 7. With a $0.5 \mathrm{~m}$ antenna, the Ka-band receiver requires a system noise temperature no greater than $322 \mathrm{~K}$ and the S-band receiver requires no greater than $290 \mathrm{~K}$. Because $290 \mathrm{~K}$ is the standard system noise temperature (Ref. 21), it was determined that a $0.5 \mathrm{~m}$ antenna would allow the LCP to meet the requirements for all three links.

\subsubsection{Final LCP Design}

To validate that the selected parameters for each link provided adequate coverage, STK was used to generate coverage maps for each link. The three coverage maps are shown in Figures 8(a), (b), and (c).

The coverage maps show the relative amounts of access time for different areas of the lunar surface. The colors on each map show the total percentage of time that the area has communication access during the $3 \mathrm{yr}$ mission. A darker color indicates more access time. The maps reveal that both the far side and near side of the southern hemisphere can be provided relay communications and that the access time in this region increases the closer a surface asset is placed to the South Pole. Both of these characteristics are 
desirable, as the majority of the science performed by surface assets would be done close to the poles, while the capability to support surface assets anywhere in the southern hemisphere also exists.

The finalized parameters are shown in a block diagram describing the entire LCP, Figure 9.

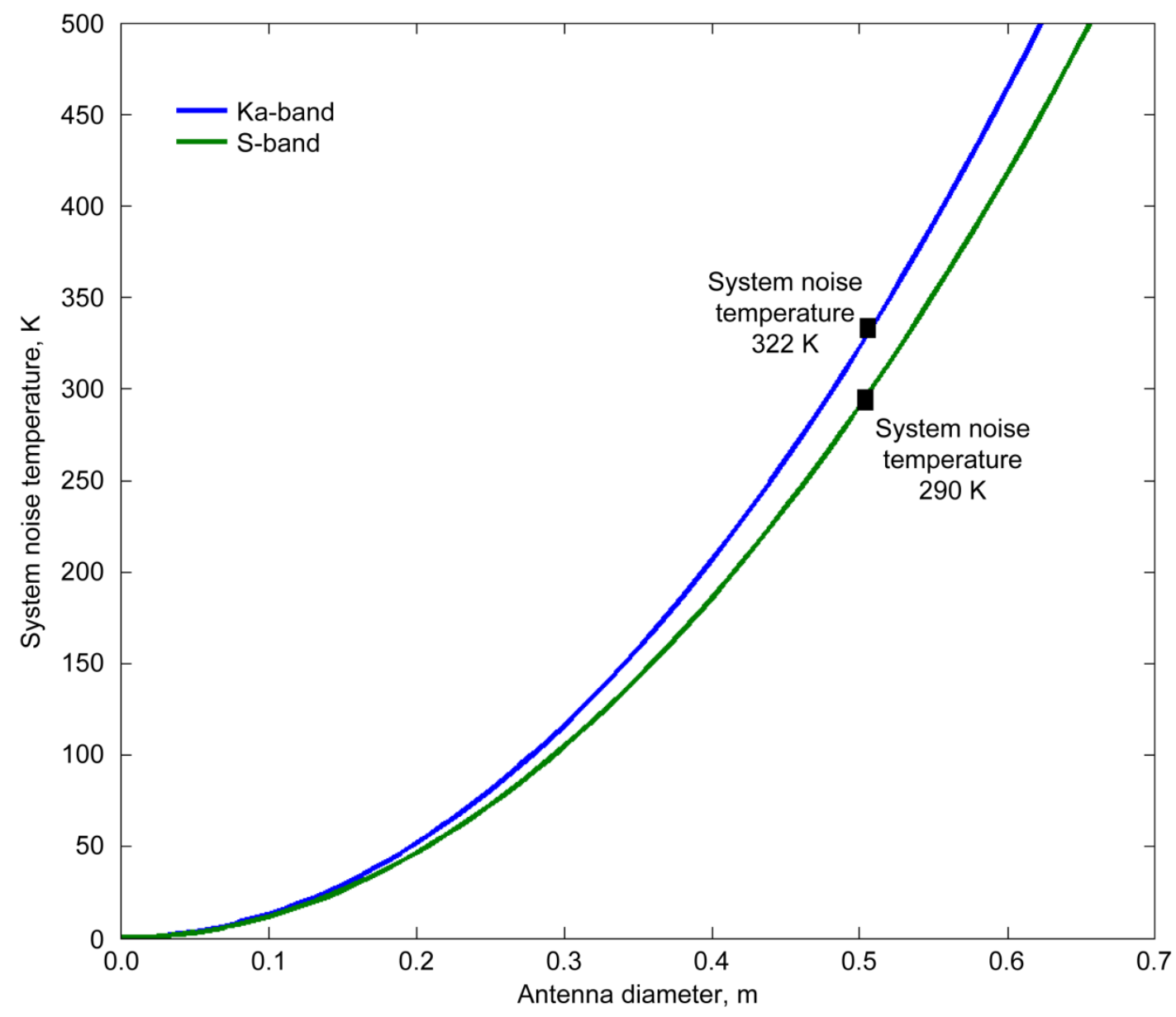

Figure 7.- System noise temperature versus antenna diameter. S-band, $\mathrm{G} / \mathrm{T}$ of $-5.8 \mathrm{~dB} / \mathrm{K}$ and frequency of $2.25 \mathrm{GHz}$. Ka-band, G/T of $15 \mathrm{~dB} / \mathrm{K}$ and frequency of $26 \mathrm{GHz}$.

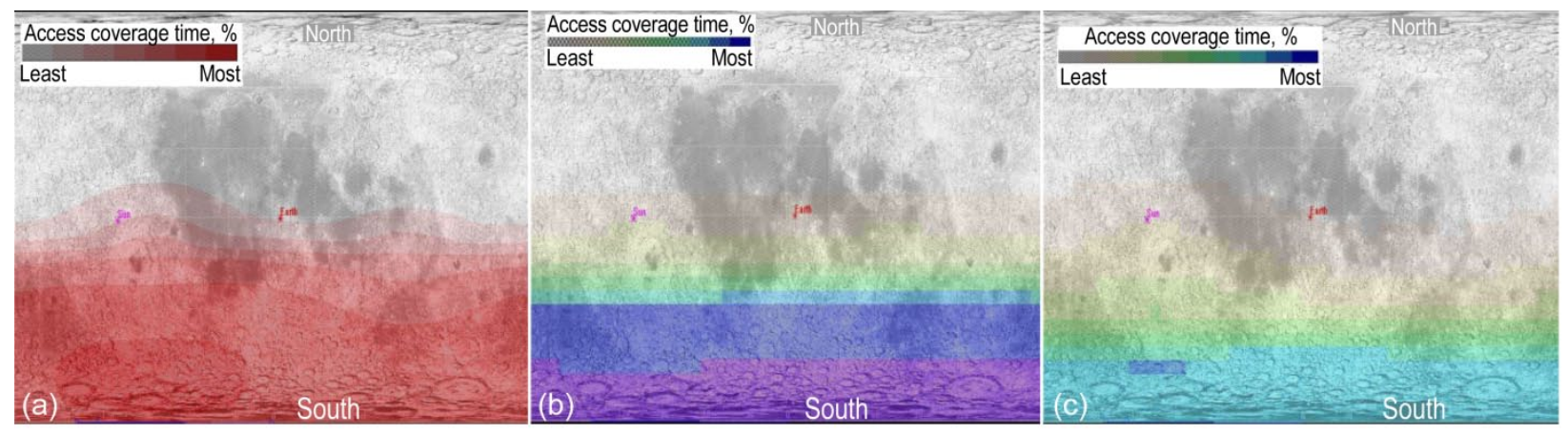

Figure 8.-Lunar coverage maps. (a) Ka-band receiver coverage; (b) S-band receiver coverage; and (c) S-band transmitter coverage. 


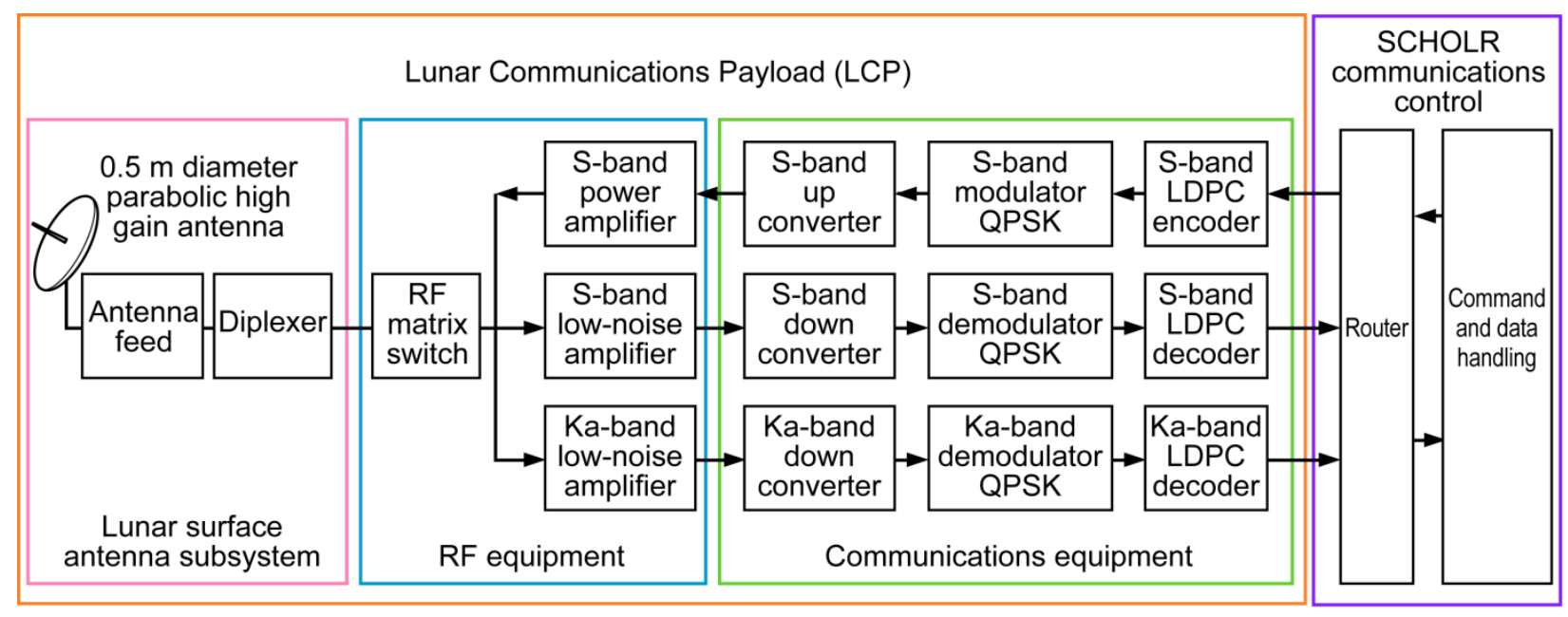

Figure 9.-Block diagram for LCP.

By utilizing different frequencies and an RF matrix switch for all three of the links, each communication link can use the same $0.5 \mathrm{~m}$ high gain parabolic antenna. The S-band transmitter uses a solid-state amplifier to produce the transmit power needed to close the links. The two receivers each use a low noise amplifier in order to pick up the signals from the lunar surface asset. The data entering and leaving the LCP is sent by the C\&DH system to a router that decides which path the information should take to reach the correct place. The final design parameters are summarized in Table 4.

TABLE 4.-LCP LINK PARAMETERS

\begin{tabular}{|l|c|c|c|}
\hline \multicolumn{1}{|c|}{ Parameters } & S-band receive & S-band transmit & Ka-band receive \\
\hline Frequency, GHz & 2.25 & 2.1 & 26 \\
Transmit power, $\mathrm{W}$ & 5 & 4.8 & 5 \\
Polarization & RHCP & RHCP & RHCP \\
Transmit antenna gain, dBi & 14.4 & 18.2 & 35.6 \\
EIRP, dBW & 21.4 & 25 & 42.6 \\
Receive antenna gain, dBi & 18.8 & 13.8 & 40.1 \\
System noise temperature & 290 & 290 & 322 \\
G/T, dB/K & -5.8 & -10.8 & 15 \\
Data rate, Mbps & 2 & 2 & 100 \\
Required $\mathrm{E}_{\mathrm{b}} / \mathrm{N}_{0}, \mathrm{~dB}$ & 2.6 & 2.6 & 2.6 \\
Required $\mathrm{E}_{\mathrm{b}} / \mathrm{N}_{0}$ with link margin, $\mathrm{dB}$ & 5.6 & 5.6 & 5.6 \\
\hline
\end{tabular}

The LCP is able to provide the three links necessary to allow lunar surface assets to communicate with SCHOLR. Simulation of the scenario in STK confirms the SCHOLR LCP could provide service to lunar surface elements while meeting all of the link requirements.

\subsection{Mission Orbit Determination}

SCHOLR's orbit is an integral contributor to meeting stakeholder requirements as it defines what functions SCHOLR will be capable of performing. It affects the operation of both the SIP and the LCP. For both mission objectives, scientific data gathering and communications relay, SCHOLR requires an orbit which passes over the lunar poles. The resolution of the sensors in the SIP is directly related to the altitude at which the measurements are taken. Each sensor chosen to fly aboard SCHOLR requires an orbit altitude near $100 \mathrm{~km}$. A communications relay needs a relatively long access time (i.e. time during which SCHOLR is in sight of the surface elements) to be effective. This implies that SCHOLR must be at a high altitude within the surface elements' line-of-sight to the LCP. 
There is a major challenge inherent in designing an orbit for a hybrid science and communication satellite like SCHOLR. The conflicting needs of the two payloads for different altitudes make global hybridization practically impossible with current technology. Therefore, a solution is needed that satisfies SCHOLR's requirement to be a hybrid orbiter. That solution is temporally isolated hybridization, in which SCHOLR performs both data gathering and communications relaying, but does so within separate portions of the orbit.

\subsubsection{Orbit Trades}

Over the course of the orbit determination process, three main trades were investigated. The trade selected for SCHOLR, a highly elliptical polar orbit (Trade 3, cyan orbit in Fig. 10), was determined to be the option best suited for the mission. It combines a low periapsis altitude at the lunar North Pole and a high apoapsis altitude at the lunar South Pole. The low periapsis altitude, approximately $100 \mathrm{~km}$, is in accord with the range limitations of the SIP. The high apoapsis altitude, approximately $5798 \mathrm{~km}$, enables a communication link to be established from SCHOLR to any surface node in the southern hemisphere for over $5 \mathrm{hr}$, a period long enough to forward stored data and facilitate teleoperation of surface elements from Earth.

An elliptical lunar frozen orbit (Trade 1 white orbit in Fig. 10) was not feasible because an orbit with an inclination of $90^{\circ}$ must have an eccentricity of 1.0 to be a frozen orbit (Ref. 22). In that case, the orbit would be parabolic: an escape trajectory. Alternatively, if the $90^{\circ}$ inclination is sacrificed for a practical eccentricity, the orbit no longer passes above the lunar North Pole.

Although the circular path and low $100 \mathrm{~km}$ altitude of the Trade 2 orbit, seen in orange in Figure 10, allowed for the best range and pass duration for the SIP, it also severely limited communication applications. SCHOLR could initially fly this $100 \mathrm{~km}$ orbit and boost to a higher orbit after the $3 \mathrm{yr}$ of its primary mission. This operation could provide better relay capabilities during SCHOLR's extended mission. However, the delta-V required to capture into low lunar orbit and later move to a higher orbit, nearly $1.5 \mathrm{~km} / \mathrm{s}$ in total (compared to only $500 \mathrm{~m} / \mathrm{s}$ for capture into the Trade 3 orbit), made the option undesirable.

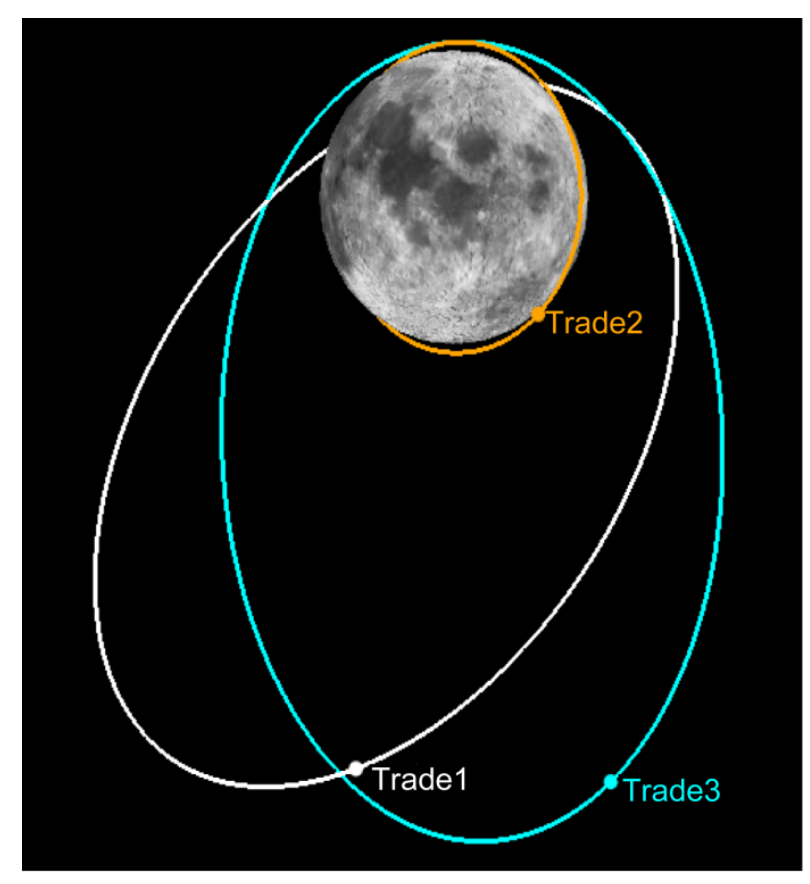

Figure 10.-Comparison of primary mission orbit trades. Trade3 is the orbit selected for SCHOLR. 
The orbit finally selected for the SCHOLR primary mission, summarized in Table 5, was an 8-hr elliptical polar orbit. The $8 \mathrm{hr}$ period was selected to enable the fulfillment of both science and communication goals and to complement the work schedules of ground crews supporting the SCHOLR mission.

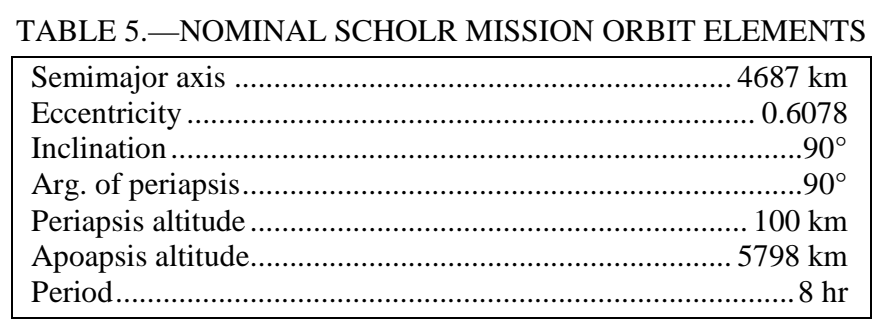

\subsubsection{Orbit Decay Analysis}

In order to study mission lifetime and provide data for propellant usage analysis for SCHOLR, the orbit was modeled using STK (Ref. 19) and Satellite Orbit Analysis Program (Ref. 23) with third body perturbations to simulate orbit degradation due to forces not accounted for in traditional two body mechanics. The simulated orbit was permitted to decay until it intersected the lunar surface, implying SCHOLR would impact the Moon, as seen in Figure 11. Working back from that point, it was determined, based on standard practices and the simulation results, that a station-keeping maneuver would be performed every time the periapsis altitude reached $50 \mathrm{~km}$. Based on this assumption, a burn of $5.6 \mathrm{~m} / \mathrm{s}$ delta- $\mathrm{V}$ would be required approximately every fourteen days. Therefore, over the nominal 3 yr SCHOLR mission, a delta-V totaling $437 \mathrm{~m} / \mathrm{s}$ would be required to keep the satellite in orbit around the Moon. An additional $952 \mathrm{~m} / \mathrm{s}$ would be needed for launch vehicle injection for lunar transfer orbit, mid-course corrections, lunar orbit capture, and the maneuver to enter the extended mission orbit (Ref. 24).

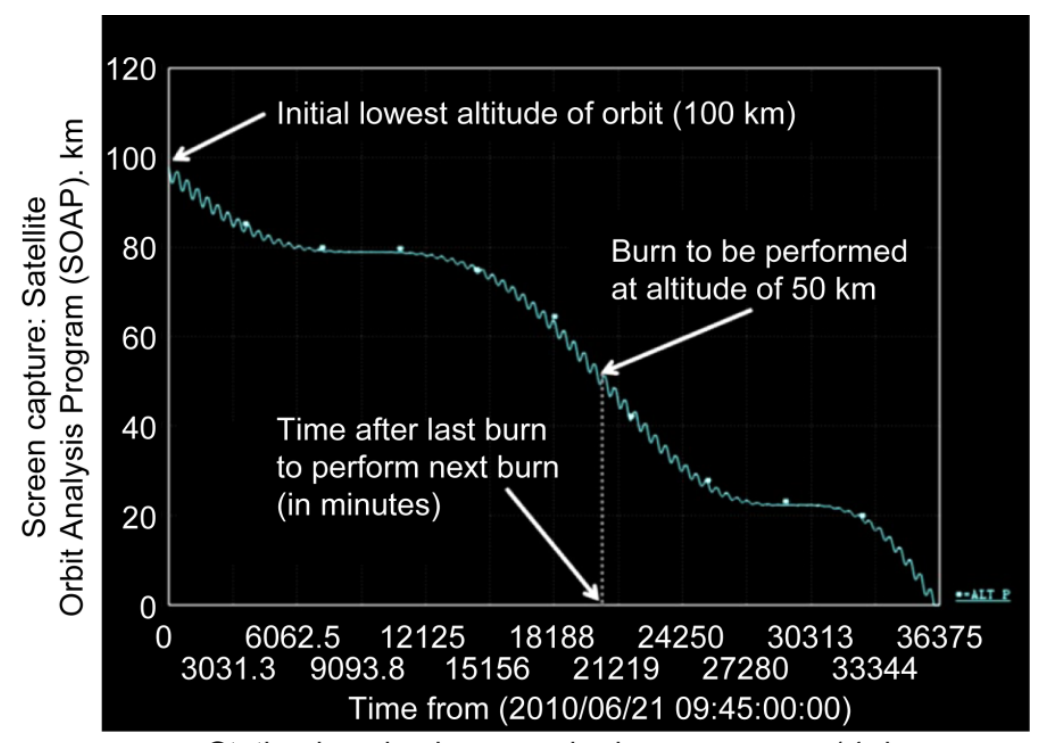

Station-keeping burn required every approx. 14 days

Figure 11.-Periapsis altitude as function of time (orbit decay). 


\subsubsection{Spacecraft Pointing}

SCHOLR's temporally isolated hybridization influenced the configuration of the spacecraft. Due to competing altitude requirements, the payloads could not function simultaneously. To enable hybridization, SCHOLR was designed to be inertially pointing and configured with the external components of the SIP and LCP on opposite sides of the spacecraft bus. With the satellite always oriented to the lunar poles, the spacecraft face with the SIP would always face the lunar surface as it passes over the North Pole. Similarly, the side with the LCP would always view the lunar surface as it passes over the South Pole. This additionally establishes an axis of rotation about which SCHOLR can spin to track Earth with its Earth antenna. Continuously pointing the Earth antenna in this manner reduces risk and propellant usage over typical operations that involve flipping maneuvers to keep Earth in view (Ref. 6).

\subsection{SCHOLR Subsystem Design}

\subsection{Subsystem Integration}

A conceptual design for each of SCHOLR's subsystems was performed after the mission architecture, payloads, and orbit were determined. To ensure that the subsystems would function both independently and collectively to accomplish SCHOLR's mission, the mass, dimensions, power consumption, and pointing needs for each subsystem were tracked throughout the design phase. If any subsystem's demands conflicted with another subsystem's limitations, the integration process mediated discussions to strike a compromise. In this way, the integration process prevented subsystem incompatibility, thus supporting the success of the entire satellite system.

The primary means of subsystem organization and analysis was the Master Equipment List (MEL). As subsystem was specified, component details were entered and updated in the MEL. A condensed view of the MEL can be found in Table 6.

TABLE 6.-SCHOLR OVERVIEW SNAPSHOT OF THE MEL.

[Note that only one of eight power configurations is displayed.]

\begin{tabular}{|l|r|r|r|r|r|}
\hline \multicolumn{1}{|c|}{$\begin{array}{c}\text { Description } \\
\text { SCHOLR Communications Spacecraft }\end{array}$} & $\begin{array}{c}\text { Basic mass } \\
(\mathrm{kg})\end{array}$ & $\begin{array}{c}\text { Growth } \\
(\%)\end{array}$ & $\begin{array}{c}\text { Growth } \\
(\mathrm{kg})\end{array}$ & $\begin{array}{c}\text { Total mass } \\
(\mathrm{kg})\end{array}$ & $\begin{array}{c}\text { Power } \\
\text { mode 3 } \\
(\mathrm{W})\end{array}$ \\
\hline SCHOLR Spacecraft & 1870.73 & 8.8 & 164.95 & 2035.67 & 1020 \\
Science Payload & 74.20 & 28.2 & 20.95 & 95.15 & 230.4 \\
Attitude Determination and Control & 40.52 & 20.0 & 8.10 & 48.62 & 207.0 \\
Command and Data Handling & 59.40 & 23.7 & 14.09 & 73.49 & 163.3 \\
Communications and Tracking & 92.51 & 10.0 & 9.25 & 101.77 & 305.3 \\
Electrical Power Subsystem & 86.00 & 25.8 & 22.20 & 108.20 & 0.0 \\
Thermal Control (Non-Propellant) & 197.47 & 15.2 & 30.10 & 227.56 & 13.0 \\
Propellant (Chemical) & 874.91 & 0.0 & 0.00 & 874.91 & 0.0 \\
Structures and Mechanisms & 362.38 & 14.1 & 51.09 & 413.46 & 0.0 \\
\hline
\end{tabular}

The MEL maintained characteristics such as mass, growth percentage, power consumption, operating temperatures, and basic dimensions. These measures provided a general overview of the satellite design and indicated violation of any critical restrictions, such as total mass or total power consumed. The utilization of the MEL during the design process allowed for quick and collaborative design and analysis of the satellite.

\subsection{Structural Subsystem}

The structures of SCHOLR must support and protect the spacecraft's components from dynamic environments during all mission phases: pre-launch, launch, deployment, operations, and disposal. The key elements that drive the structures of the spacecraft include the packaging concepts, deployable 
structures, materials, and volume to ultimately keep the payload safe and functional. These decisions are made based upon the mission's goals, requirements, constraints, and payload configuration drivers.

\subsubsection{Subsystem Requirements}

Each component must be in a position that allows it to perform properly and satisfy mission requirements. The structures subsystem must support the spacecraft's components in these desirable locations. SCHOLR must additionally deploy any necessary components while providing enough stiffness to keep them steady. This would allow the deployed components to achieve optimal performance. The structures must also provide sufficient support for all loads and vibrations during mission phases. It must prevent the spacecraft from collapsing, damping, or affecting the components. Furthermore, the structure material must protect each component from radiation, pressure, impacting particles, and thermal cycling (Ref. 25).

Structure requirements were derived from the mission requirements and in consideration of the types of spacecraft components that would require support. The general shape and dimensions were estimated for the main bus structure, as seen in Figure 12. A packaging configuration of all the components within the spacecraft was then developed. This consisted of identifying subsystem requirements for size, fields of view (FOV), mechanisms, and deployable structures. Finally, the material for each structure was selected.

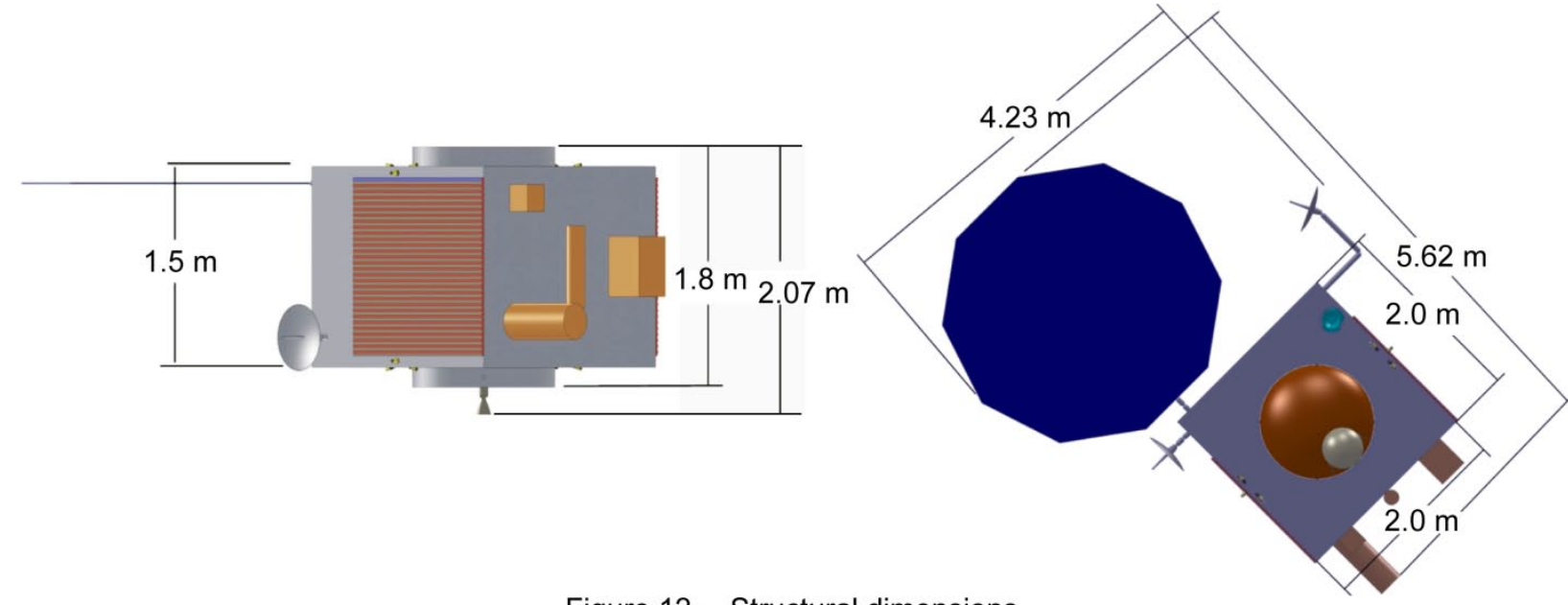

Figure 12.-Structural dimensions.

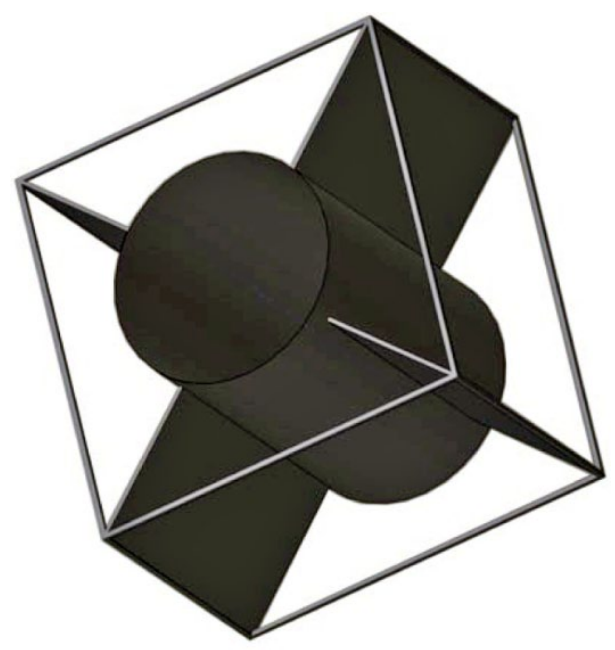

Figure 13.-SCHOLR main bus structure. 


\subsubsection{Structure Design}

The type of structure for the main bus first determined SCHOLR's structural system. A thrust tube design with inner panels, seen in Figure 13, was chosen for simplicity, strength, and adaptability to the launch vehicle payload adaptor. The thrust tube would house the main fuel tank, pressurant tank, and main thruster. The material was chosen to be aluminum lithium alloy, specifically aluminum 2090-T83. This has a high strength-to-weight ratio, high technology readiness level (TRL), and low cost. Honeycomb sandwich panels would be used on the inner panels connected to the thrust tube and the outer side panels for mounting components. Honeycomb panels were chosen for mounting components because they provide a high bending strength and stiffness for a low mass (Ref. 25).

Two booms were required to deploy the radar sounder 15-m in opposite directions. ABLE Engineering coilable booms were chosen because of their high reliability, strength, and TRL; low weight, and small-stowed size. A continuous-longeron boom was chosen because the boom was not restricted to a certain diameter. A continuous-longeron boom also provides high dimensional stability and a high stiffness-to-weight ratio. A lanyard deployment mechanism was chosen over a canister deployment mechanism because it weighs less and the stowage volume is smaller in length and diameter (Ref. 26).

\subsubsection{Configuration Design}

Characteristics such as location, mass properties, size, mechanical interfaces, fields of view, and thermal interfaces for all components must be considered to determine the best layout for the spacecraft and its components. This entails integrating each subsystem's components to create the design that allows maximum performance of the spacecraft. The main design drivers for the configuration are the propulsion tank sizes and the fields of view for the science instruments, antennas, and solar array (Ref. 27).

The configuration was derived from the subsystem requirements and constraints. Design parameters and a preliminary spacecraft design were then estimated based on these subsystem concepts. The Falcon 9 payload fairing, shown in Figure 14, drove the size of SCHOLR. Budgets for quantity, size, and mass of each component were then established in the MEL. A structural architecture and design for packaging the components was then selected and created in the computer-aided design software, SolidWorks (Ref. 28).

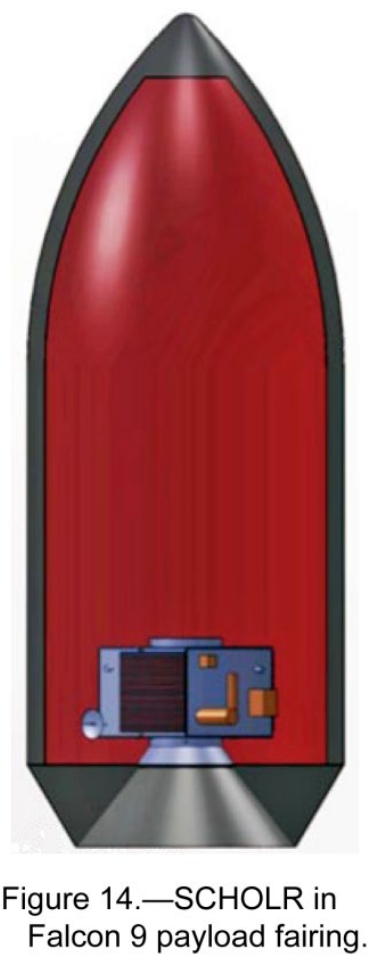




\subsubsection{Configuration Constraints}

The location of the outer components of the SIP and LCP were constrained by their pointing requirements. The SIP should face the Moon when SCHOLR is at the North Pole, and the LCP should face the Moon when SCHOLR is at the South Pole. SCHOLR's inertial pointing constrained the configuration of the external components because different spacecraft faces view the Moon at different parts of the orbit. This directly affected the FOV for specific components.

Another constraint was the available area to place external components. For example, it was necessary for the radiators to be a certain size to adequately control the spacecraft temperature. A conflict arose because of the noise introduced to the communications link by radiators located near antennas. The lunar antenna would be deployed on a boom to avoid the FOV of the radiators, and the Earth antenna would be gimbaled to avoid thermal radiation. Similar constraints exist with the solar array, SIP, LCP, radiators, guidance sensors, and propulsion.

SCHOLR's internal configuration was heavily influenced by the size of the propulsion tanks, the heaviest and largest components. Other components, whose volumes were tracked in the MEL, must be secured to the spacecraft bus and fit within the spacecraft's skin. Component locations were also driven by thermal interfaces from the thrusters, battery, and radiators. Optimal functionality considerations shaped the internal placement of components, heat pipes, and electrical and data connections.

\subsubsection{Final Configuration}

SCHOLR's final deployed configuration is shown in Figure 15. The stowed configuration design is shown in Figure 16 and the internal configuration can be seen in Figure 17. The FOV is sufficient for the mission objectives of the antennas, solar array, star trackers, and scientific instruments. The science instrument locations are shown in Figure 18. The radar sounder was placed in the center of the side panel to help balance the mass distribution. The UltraFlex solar array, Earth and lunar antennas, and coilable booms for the radar sounder were all analyzed to best determine the stowed and deployed configurations of the spacecraft. There are two Sun sensors placed on each side of the craft to provide full omnidirectional coverage. This allows the sensors to have a constant FOV of the Sun.

The subsystems are grouped together within the spacecraft to ensure simplicity during assembly. There is adequate space left around each component for wiring and installations. Doors are provided on the side panels to provide technicians access to the components during assembly. Each component is packaged in a location that would allow it to best perform its mission objectives. Every component would function within its operating temperature.

The C\&DH system was placed near the center of the spacecraft because it is the interface between all the subsystems. The main thruster was positioned through the spacecraft's center of mass to reduce the complexity of attitude control. Table 7 shows the final design details.

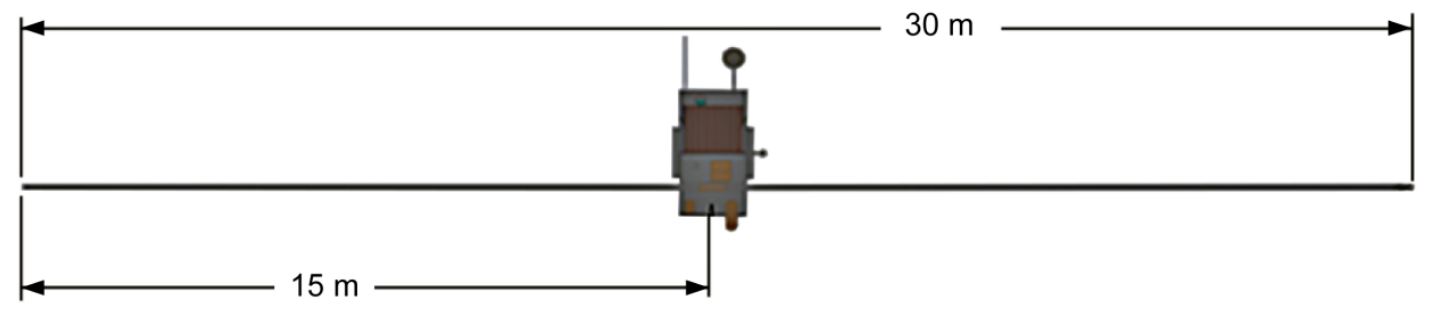

Figure 15.-SCHOLR deployed configuration. Depiction of the deployed booms of the radar sounder. 


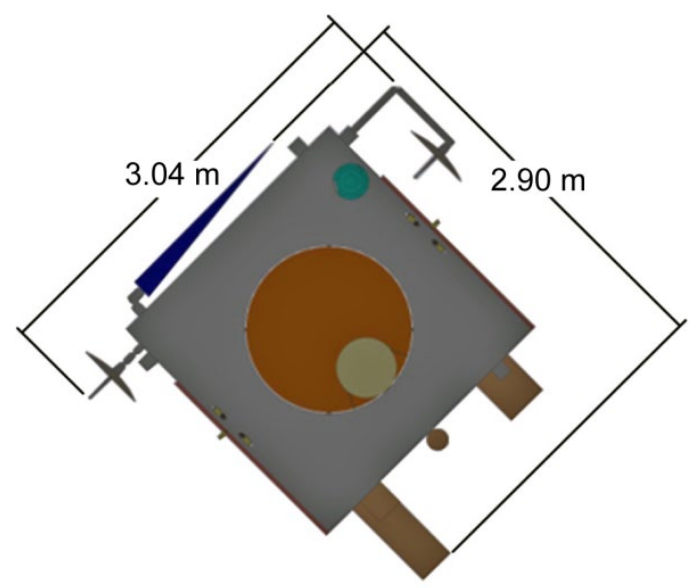

Figure 16.-SCHOLR stowed configuration.

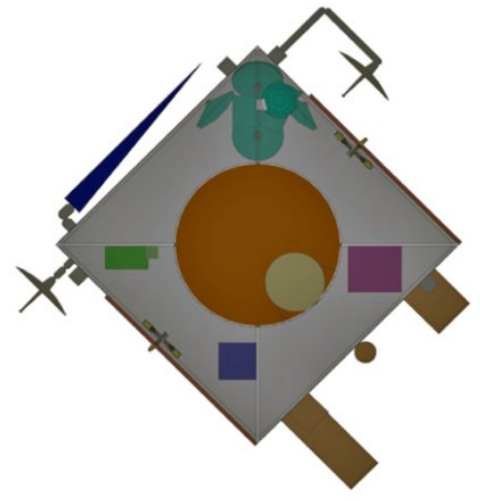

Figure 17.-SCHOLR interior configuration.

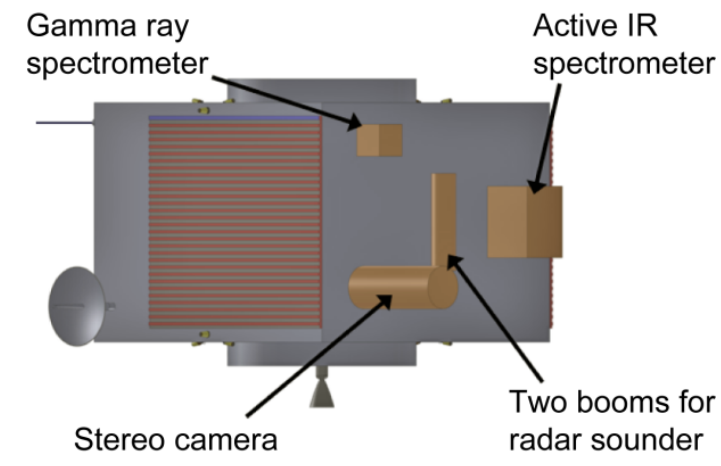

Figure 18.-SCHOLR science instruments.

TABLE 7.-FINAL STRUCTURE AND CONFIGURATION DESIGN DETAILS

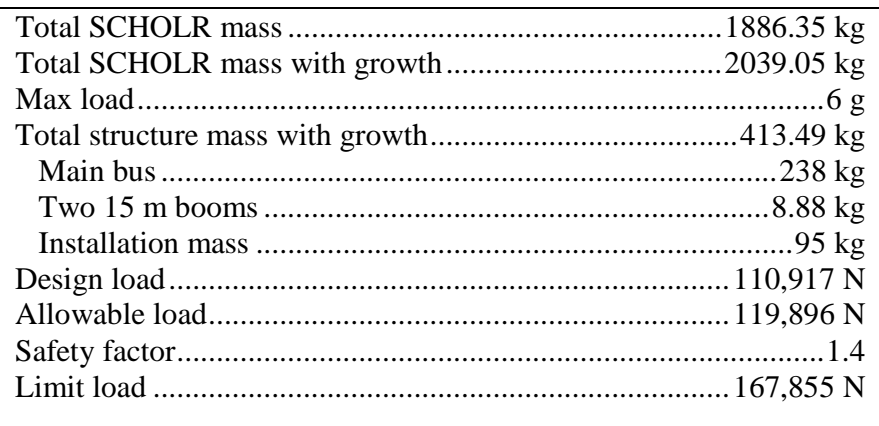

Aluminum lithium alloy (Al 2090-T83) honeycomb sandwich panels

Two $15 \mathrm{~m}$ continuous-longeron booms with lanyard deployment 


\subsection{Environmental Control Subsystem}

The SCHOLR Environmental Control Subsystem (ECS) ensures the spacecraft temperature will remain within the operational limits of the on-board instruments and that the spacecraft will safely operate within the lunar orbit environment. The main element of the ECS, the thermal control subsystem, rejects excess heat or generates required heat according to the thermal operational limits of the spacecraft components. The rest of the ECS shields the spacecraft from the lunar orbit environment, including unwanted radiation and micro meteors, through use of a variety of passive systems.

\subsubsection{Thermal Subsystem Design}

\subsubsection{Thermal Requirements}

The thermal subsystem must maintain the spacecraft components and structural interfaces within their operating temperature ranges during all mission phases. To accomplish this, the thermal subsystem must provide a means of cooling the spacecraft during operation as well as provide heat to vital components and systems to preserve their functionality. The maximum heat load to be rejected by the thermal system is 1312 Watts thermal $\left(\mathrm{W}_{\mathrm{t}}\right)$, and the desired operating temperature for the radiators is $320 \mathrm{~K}$.

\subsubsection{Thermal Assumptions}

The thermal modeling process provides mass and power estimates for the various aspects of the thermal control system based on a number of inputs related to the vehicle geometry, flight environment and component size. The assumptions utilized in the analysis and sizing of the thermal subsystem were based on the operational environment of the spacecraft. Since SCHOLR would operate in a highly elliptical polar lunar orbit with a periapsis of $100 \mathrm{~km}$, the following assumptions were made to size the thermal subsystem:

- The view factors for the radiator to the Earth, lunar surface and solar array were assumed to be $0.1,0.35$ and 0.1 respectively

- The maximum angle of the radiator to the Sun was $30^{\circ}$

- The direct energy transfer (DET) from the solar panels to the instruments is 85 percent efficient during times of insolation and 65 percent efficient during eclipses, when batteries supply power (Ref. 29)

- Typical parabolic antennas convert 55 percent of the power provided to them into RF energy that carries the communications signal to Earth and therefore does not need to be rejected through the radiators (Ref. 30)

- The radiation heat transfer equation, based on the Stefan Boltzmann law, was used to size the radiators (Ref. 31)

\subsubsection{Radiator Design}

The primary component of the thermal subsystem is the radiator, which regulates the spacecraft temperature by rejecting excess heat. Most of the heat that must be controlled or rejected is produced when electrical power from the solar array is converted to heat due to the internal resistance of spacecraft instrumentation. Both waste heat from the satellite and environmental radiation are rejected by infrared radiation from the surface of the radiators.

The thermal power to be rejected from the craft was determined by the power consumed by the spacecraft during each stage of the mission. Considering each of these factors, the maximum amount of power to be rejected at any time is $1312 \mathrm{~W}_{\mathrm{t}}$, as seen in Figure 19.

The radiating temperature was determined by the desired operating temperature of the internal instruments. The sink temperature of $260 \mathrm{~K}$ was estimated using information about the environment during SCHOLR's mission. A reflective coating with a high infrared emissivity (0.84) was chosen to cover the radiators to protect them from environmental radiation. 
The radiator for SCHOLR was sized by solving the heat transfer equation for the radiator area required to reject the excess heat generated within the spacecraft. These calculations returned a required radiator area of $4.7 \mathrm{~m}^{2}$, which is too large to fit on the given $3.0 \mathrm{~m}^{2}$ side of the spacecraft. Therefore, trade studies were performed to determine the best way to accommodate the large amount of thermal power that must be rejected from the craft.

\subsubsection{Radiator Trades}

Multiple trades were considered for the radiator design for SCHOLR. Design ideas investigated included: the use of louvers in addition to a radiator, a deployable radiator, two radiators radiating at the same temperature, and one radiator using phase change material (PCM). It was determined that louvers should not be used because they obscure the radiator's view to deep space, increasing the required radiator area by 30 percent. Although using a deployable radiator would provide twice the radiating area for the same effective stowed size, it was deemed to be significantly too complicated and costly for the spacecraft and therefore was not implemented. A trade study was performed on the use of PCM to determine if this method would sufficiently reduce the radiator area, allowing the radiator to fit on one side of the spacecraft.

The goal of the PCM study was to determine the mass of PCM that would be required to allow the use of a single radiator. The maximum power that could be rejected from a radiator constrained to one side of the spacecraft was calculated to be $775 \mathrm{~W}_{\mathrm{t}}$. Figure 19 shows the excess power to be dissipated using PCM if only one radiator were to be implemented. Since the original power to be dissipated was $1312 \mathrm{~W}_{\mathrm{t}}$, the PCM would have to absorb $537 \mathrm{~W}_{\mathrm{t}}$. Assuming a 3-hr dissipation time due to SCHOLR's orbit and a PCM heat of fusion of $215 \mathrm{~kJ} / \mathrm{kg}$, dimensional analysis determined $27 \mathrm{~kg}$ of PCM was required. An additional $8 \mathrm{~kg}$ of structure supports the PCM, increasing the total mass to $35 \mathrm{~kg}$. Based on the mass constraints imposed by SCHOLR's Falcon 9 launch vehicle, the PCM could not be used to decrease the radiator area because of the required increase in mass.

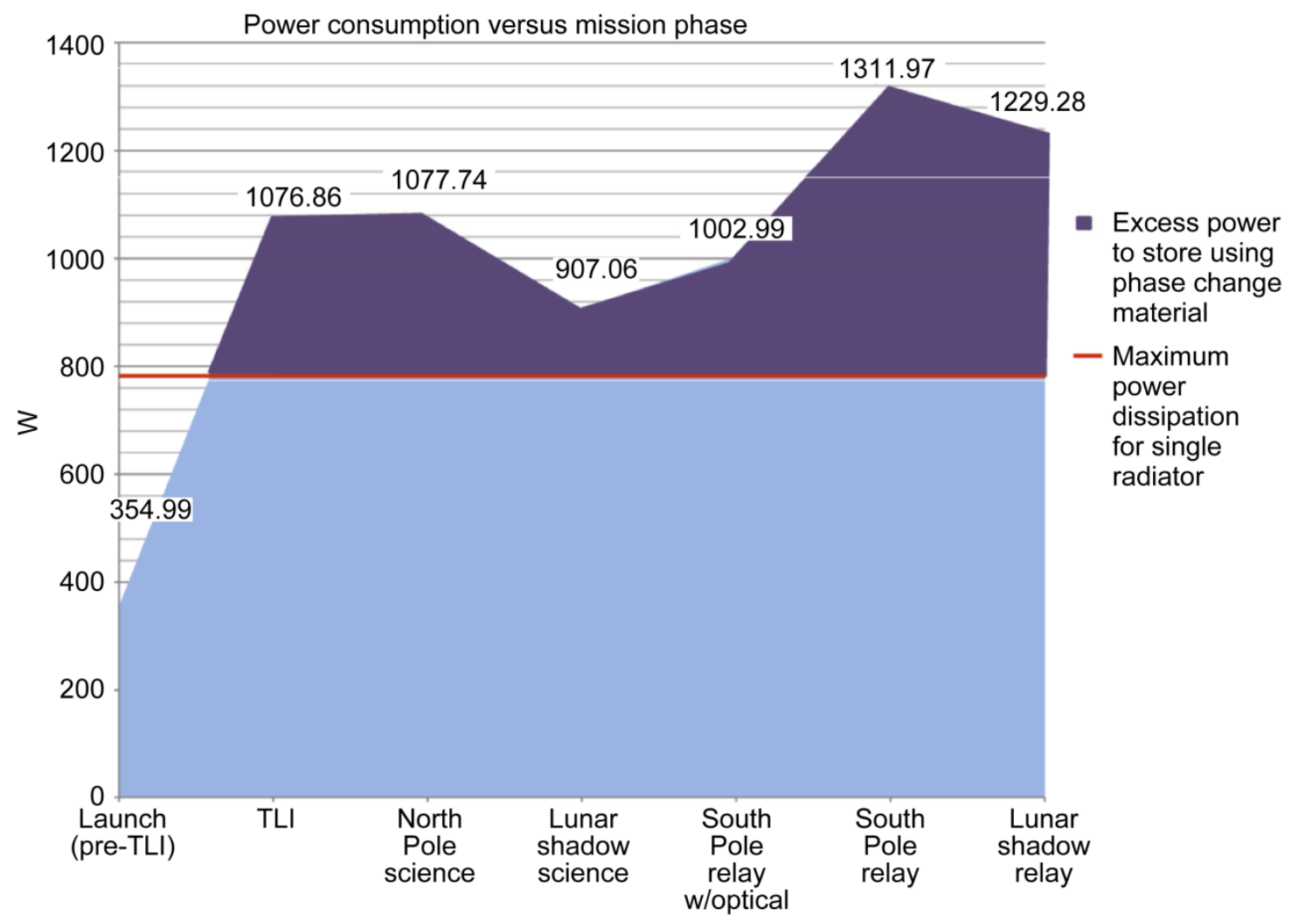

Figure 19.-Power to be radiated during each mission phase. 


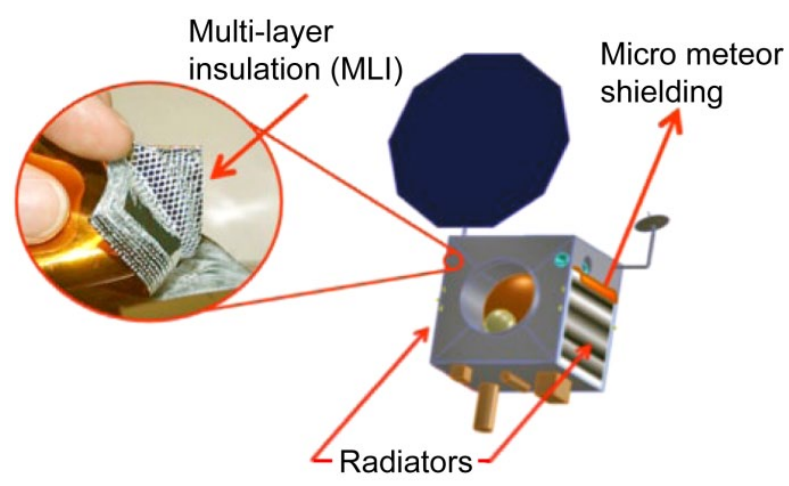

Figure 20._-Thermal subsystem external components.

\subsubsection{Final Environmental Control Design}

SCHOLR would incorporate two $2.3 \mathrm{~m}^{2}$ radiators that radiate at the same temperature. Improved radiator efficiency can be realized by maximizing spacecraft pointing at deep space and minimize pointing at celestial bodies such as the Moon, Earth, and Sun. Therefore, the radiators are mounted on opposing sides of the spacecraft as shown in Figure 20.

Other components of the ECS include micrometeor shielding, which protects the junction between the heat pipes and radiators and multi-layer insulation to insulate the craft, enabling accurate thermal control and external coatings to reflect excess heat and radiation. Lastly, electric heaters and a control system were also selected for the subsystem management. SCHOLR's ECS consists of active and passive controls as part of its design, as shown in Table 8.

TABLE 8.-ACTIVE AND PASSIVE CONTROLS

\begin{tabular}{|l|l|}
\hline \multicolumn{1}{|c|}{ Active thermal control } & \multicolumn{1}{c|}{ Passive thermal control } \\
\hline Variable heat pipes & Radiators \\
Thermal control circuit & Heat sinks \\
Data acquisition & Multi-layer insulation \\
Thermocouples & Micro meteor shielding \\
Electric heaters & Reflective surface paints \\
\hline
\end{tabular}

\subsection{Guidance, Navigation, and Control Subsystem}

The purpose of SCHOLR's Guidance, Navigation, and Control (GN\&C) subsystem is to locate, point, and rotate the spacecraft to complete its mission. The GN\&C subsystem provides attitude control of the vehicle from launch through end of mission in all three axes.

\subsubsection{GN\&C Requirements and Assumptions}

The attitude control system is responsible for maintaining SCHOLR's attitude, solar array orientation, and high gain antennas' pointing throughout the mission. The attitude control system shall correct for disturbance torques and would supply housekeeping, telemetry, attitude, and orbit determination data to the ground station. The GN\&C subsystem also controls and monitors the propulsion system. SCHOLR's products of inertia were assumed to be zero, meaning it was assumed the spacecraft's mass distribution was symmetric about the $\mathrm{x}, \mathrm{y}$, and $\mathrm{z}$ axes. SCHOLR has negligible slew requirements because of the inertial pointing designed for the orbit. SCHOLR's altitude of $100 \mathrm{~km}$ at periapsis and $5798 \mathrm{~km}$ at apoapsis factors into the calculations to size the subsystem's instruments.

\subsubsection{Disturbance Torque Considerations}

One of the major roles of the GN\&C subsystem is to ensure the craft maintains the correct attitude during each phase of the mission. Disturbance torque affects the attitude of the satellite by varying 
amounts at different points throughout the mission. Two types of disturbance torques were analyzed: gravity gradient and solar radiation torques. Magnetic field torques and aerodynamic torques were not considered for SCHOLR's lunar orbit because there is not a significant magnetic field or an atmosphere associated with the Moon to cause a disturbance during the mission.

\subsubsection{Gravity Gradient Torque}

Gravity gradient torque is caused by the difference in magnitude of the gravitational forces on the ends of the craft. Gravity gradient torque reduces by a factor of $1 / r^{3}$ as the orbit radius increases. The portion of the spacecraft that is closest to the Moon experiences a greater gravitational force than the portion farthest from the Moon, thus creating a torque on the spacecraft. This torque will rotate the spacecraft to align the minimum moment of inertia with the local vertical (Ref. 32). The more cubical a satellite is, the smaller the gravity gradient torque.

The amount of gravity gradient torque SCHOLR would experience was calculated as a function of the difference in the moments of inertia of the spacecraft. The estimated worst case scenario gravity gradient torque SCHOLR would experience is $0.00024 \mathrm{Nm}$. The momentum due to the gravity gradient torque is a cyclic torque and therefore does not build up, causing the need for momentum dumps.

\subsubsection{Solar Radiation Torque}

Solar radiation torque is a function of the craft's cross sectional area exposed to the Sun, the craft's absorption and emissivity properties, the distance between the center of mass and center of pressure, and the solar constant. A measure of the flux from incoming solar electromagnetic radiation, the solar constant is dependent on the distance from the Sun, which is $1367 \mathrm{~W} / \mathrm{m}^{2}$ near the Moon (Ref. 29). Based on these properties, SCHOLR would experience solar radiation torque of about $0.000039 \mathrm{Nm}$. The momentum due to the solar radiation torque would build up over time because it is a secular torque.

\subsubsection{Final GN\&C Design}

To counteract these torques and maintain the desired attitude, reaction wheels were implemented to stabilize the craft. The total amount of torque was used to determine the required momentum storage and wheel torque necessary to size the reaction wheels for SCHOLR. A torque margin was incorporated when choosing the reaction wheels to account for the torque generated when the antennas, solar array, and stereo camera would be gimbaled. Based on the momentum storage of the wheels sized for SCHOLR (20 Nms for each wheel) and the cyclic torque acting on the spacecraft ( $0.000039 \mathrm{Nm}$ of solar radiation torque), the wheels would be able to store the momentum for 512820 sec, or about 6 days before being dumped.

The GN\&C components and key aspects of their design are listed in Table 9. All components for SCHOLR's GN\&C subsystem have a long heritage and are space flight qualified. Using COTS products reduces the risk associated with the mission. Figure 21 depicts the components of the GN\&C subsystem and how they connect to the propulsion system through the C\&DH subsystem. The GN\&C software runs on the main $\mathrm{C} \& \mathrm{DH}$ computers.

\subsubsection{Propulsion Subsystem}

The SCHOLR propulsion subsystem enables the spacecraft to perform its mission by sending the craft where it needs to go, maintaining its attitude, and preventing SCHOLR from mission-ending collisions with the lunar surface. This subsystem is single fault tolerant where appropriate. 
TABLE 9.-GN\&C COMPONENTS

\begin{tabular}{|c|c|c|c|c|c|}
\hline Instrument & Picture & Function & $\begin{array}{c}\text { Key } \\
\text { characteristics }\end{array}$ & Qty & $\begin{array}{l}\text { Mass } \\
(\mathrm{kg})\end{array}$ \\
\hline $\begin{array}{l}\text { Inertial } \\
\text { Measurement } \\
\text { Unit } \\
\text { (Northrop } \\
\text { Grumman SIRU) }\end{array}$ & & $\begin{array}{l}\text { - Used in orientation and } \\
\text { location determination }\end{array}$ & $\begin{array}{l}\text { - Added accelerometers also allow } \\
\text { for position and velocity sensing } \\
\text { - Uses multiple gyroscopes on } \\
\text { different axes } \\
\text { - Internally redundant }\end{array}$ & 1 & 7.10 \\
\hline $\begin{array}{l}\text { Reaction Wheels } \\
\text { (Bradford W45) }\end{array}$ & & $\begin{array}{l}\text { - Attitude control and fine } \\
\text { pointing } \\
\text { - Use torque motors and } \\
\text { high-inertia rotors for } \\
\text { momentum storage } \\
\text { (Ref. 33) }\end{array}$ & $\begin{array}{l}\text { - } 20 \text { Nms of momentum storage } \\
\text { - Sized based off disturbance } \\
\text { torques experienced during the } \\
\text { mission } \\
\text { - Pyramid configuration allows } \\
\text { control over all three axes and } \\
\text { redundancy }\end{array}$ & 4 & $\begin{array}{l}6.95 \\
\text { each }\end{array}$ \\
\hline $\begin{array}{l}\text { Star Trackers } \\
\text { (Selex-Galileo } \\
\text { A-STR) }\end{array}$ & & $\begin{array}{l}\text { - Identify star patterns and } \\
\text { determine attitude based } \\
\text { on star crossings }\end{array}$ & $\begin{array}{l}\text { - Require relative stability to } \\
\text { determine inertial reference } \\
\text { - Error introduced due to sunlight } \\
\text { interference }\end{array}$ & 2 & $\begin{array}{l}3.00 \\
\text { each }\end{array}$ \\
\hline $\begin{array}{l}\text { Sun Sensors } \\
\text { (Adcole SASS } \\
\text { 15671) }\end{array}$ & & $\begin{array}{l}\text { - Used in attitude } \\
\text { determination and solar } \\
\text { array orientation }\end{array}$ & $\begin{array}{l}\text { - } 12 \text { units, two on each face } \\
\text { - Measures angle between } \\
\text { mounting base and incident } \\
\text { sunlight (Ref. } 34 \text { ) } \\
\text { - Require clear fields of view }\end{array}$ & 12 & $\begin{array}{l}0.32 \\
\text { each }\end{array}$ \\
\hline
\end{tabular}

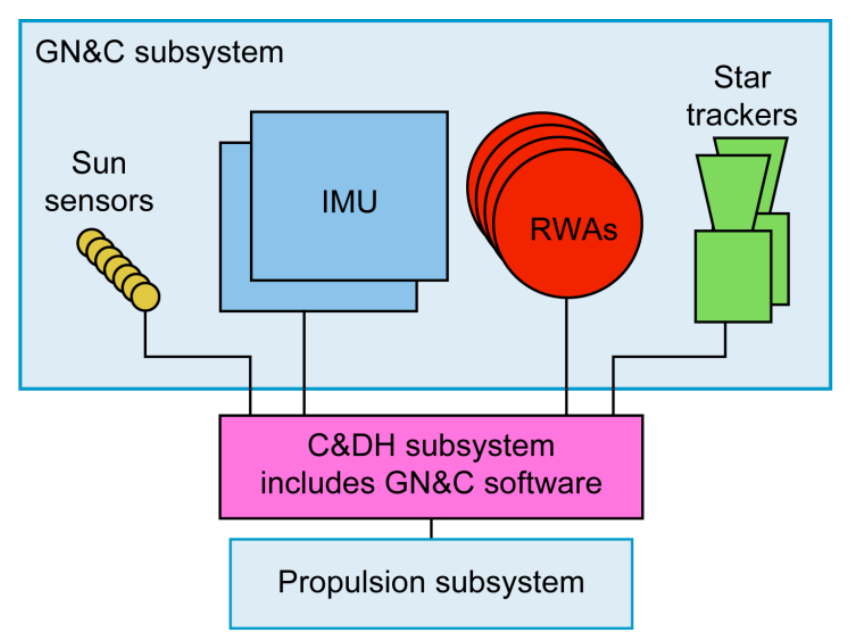

Figure 21.-GN\&C integration with other SCHOLR subsystems.

\subsubsection{Propellant Choices}

When seeking out innovative options for SCHOLR's propulsion system, green propellants were proposed as a possible solution as they are an emerging technology in-space propulsion. The first option considered was a fuel developed by Ecological Advanced Propulsion Systems, a subsidiary of the Swedish Space Corporation. High Performance Green Propellant is a monopropellant designated as LMP103S, composed of ammonium dinitramide $\left(\mathrm{NH}_{4} \mathrm{~N}\left(\mathrm{NO}_{2}\right)_{2}\right)$, water, methanol, and ammonia. This fuel has both a higher specific impulse and higher density than hydrazine, causing it to be a desirable design choice for satellite designers who are focused on performance as well as environmental impact (Ref. 35). While this fuel and these engines are space flight qualified, and the fuel is easier and safer to handle than 
hydrazine, the engines available are not large enough for the SCHOLR mission. Thus, this propulsion system was not chosen for SCHOLR.

Much activity is occurring with regards to hydrogen peroxide rocket propulsion research. This green propellant uses simple chemistry, and General Kinetics will soon have large engines that are flight qualified. Tests are underway with 250 and $1500 \mathrm{lbf}$ rockets commercially available. Unfortunately, the necessary engines are not yet available. This system was not chosen for SCHOLR due to unavailability of COTS parts.

Hydrazine is a heritage propellant in the world of satellite design. COTS parts are readily available through Aerojet and other companies; it is well researched, and is used on the Space Shuttle for attitude control. Due to the COTS design requirement, a hydrazine system was chosen as engines and parts are available in the necessary sizes for SCHOLR.

\subsubsection{Final Design}

First, an ATK 80507-3 was chosen as the main tank for the SCHOLR spacecraft. It was the appropriate size to hold the propellant necessary for the $1.5 \mathrm{~km} / \mathrm{s}$ delta-V predicted by the mission. As helium tends to leak due to its small atomic size, nitrogen was chosen as the pressurant. National Institute of Standards and Time data on nitrogen characteristics was used to calculate the mass of pressurant needed and to assist in sizing the pressurant tank. To verify this calculation, a tank was selected that could hold the entire mass of nitrogen at very high pressures. The ATK 80314-1 was selected as the pressurant tank. Due to the mission's thrust/impulsive burn requirements, a large engine was selected as the main engine. Following the Messenger mission's precedent, SCHOLR will carry only one main engine, the 100 lbf Aerojet MR-104, which enables both mass and cost savings. Smaller engines were needed for attitude control, and due to its utility in other designs (Ref. 6), the 0.5 lbf Aerojet MR-111E, shown in Figure 22, was selected to fly in four pods of three. Figure 23 depicts how these thrusters are arranged so that thrust can be sent in any of the three axes of the satellite. An internal piping diameter of $1.3 \mathrm{~cm}$ and length of $2 \mathrm{~m}$ was assumed for the main engine assembly. An internal piping diameter of $0.6 \mathrm{~cm}$ and length of $4 \mathrm{~m}$ was assumed for the reaction control system assembly. Calculations were done using actual COTS parts and data for valves, fill drain valves, filters, MLI, and pressure regulators. For heaters and sensors, simple assumptions were made to account for their mass and power usage. Table 10 shows the propulsion and propellant MEL.

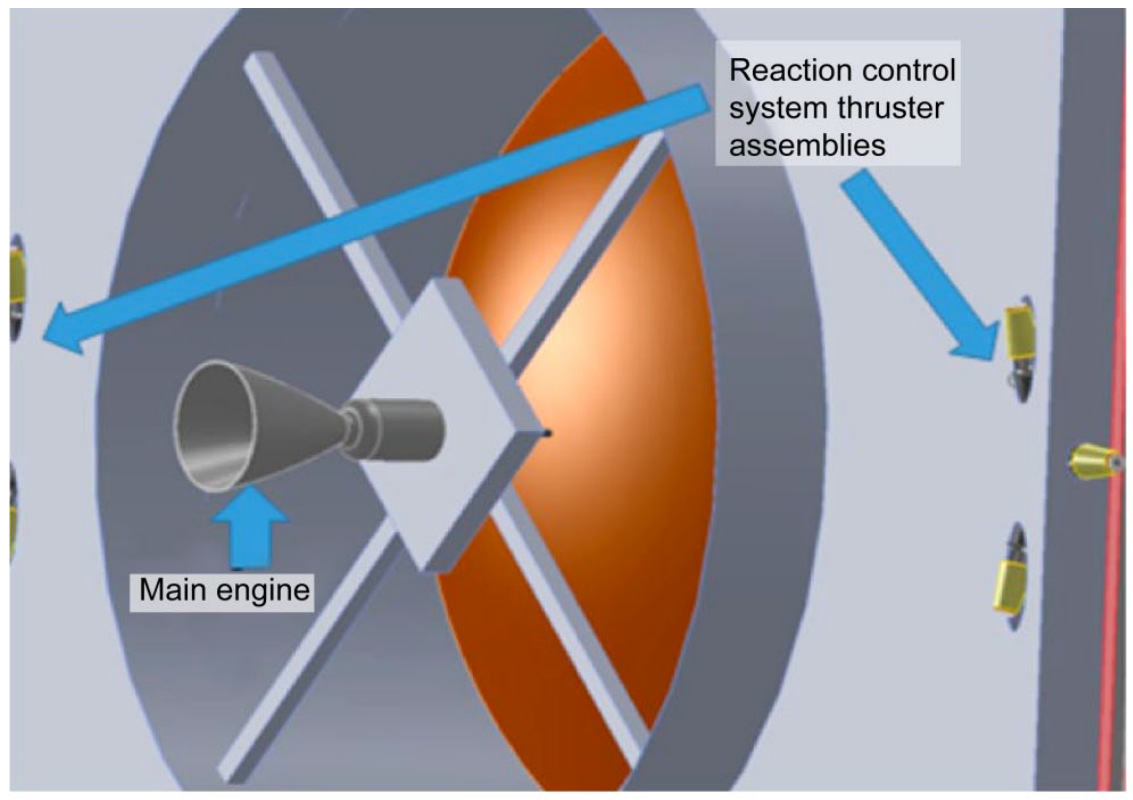

Figure 22.—SCHOLR propulsion subsystem piping and instrumentation diagram. 


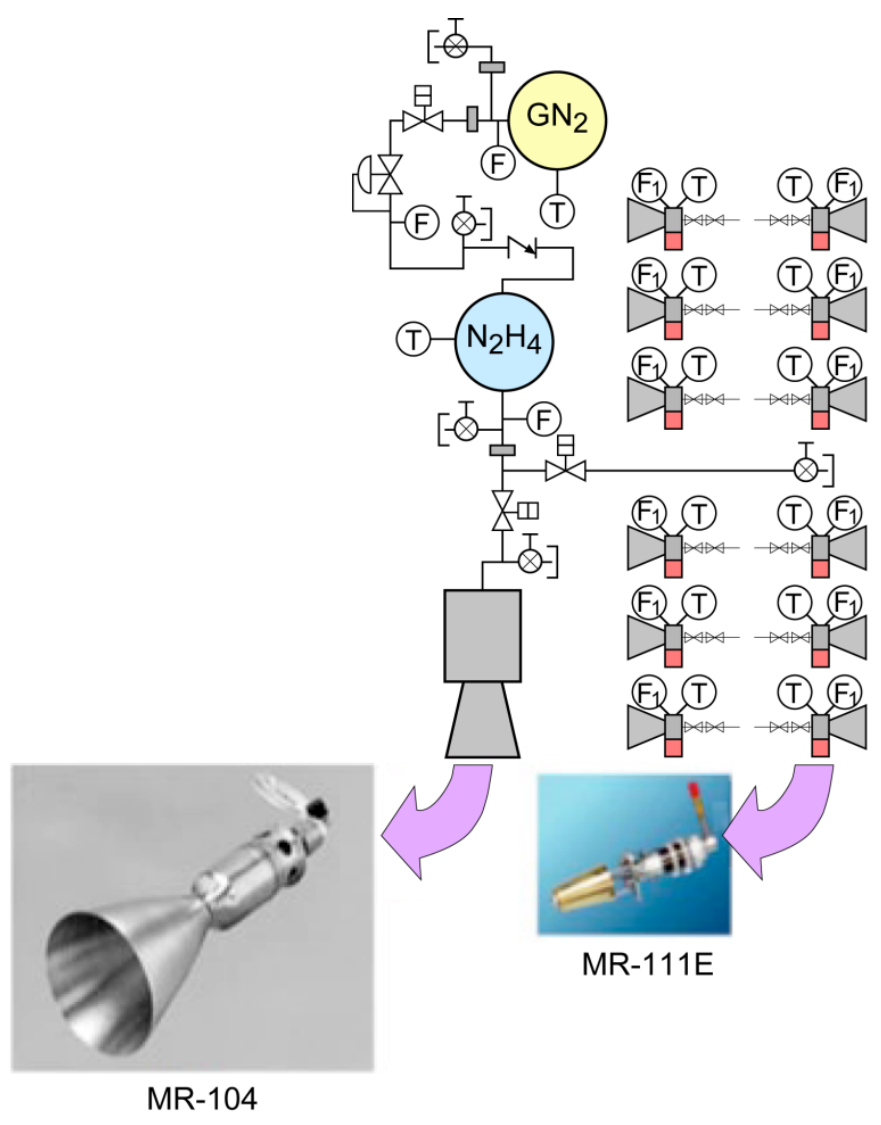

Figure 23.-SCHOLR propulsion subsystem integration diagram.

TABLE 10.-PROPULSION AND PROPELLANT MASTER EQUIPMENT LIST

\begin{tabular}{|c|c|c|c|c|c|c|}
\hline $\begin{array}{c}\text { Description } \\
\text { SCHOLR Communications Spacecraft } \\
\text { June } 2010\end{array}$ & Qty & $\begin{array}{l}\text { Total } \\
\text { mass } \\
(\mathrm{kg})\end{array}$ & $\begin{array}{l}\text { Power } \\
\text { (W) }\end{array}$ & $\begin{array}{c}\text { Shape } \\
\text { box, cylinder }\end{array}$ & $\begin{array}{l}\text { Dim } \\
\text { length } \\
(\mathrm{cm})\end{array}$ & $\begin{array}{l}\text { Dim } \\
\text { width } \\
(\mathrm{cm})\end{array}$ \\
\hline Propulsion (chemical) & & 92.51 & 197.6 & & & \\
\hline Propulsion hardware (chemical) & & 1.90 & 13.1 & & & \\
\hline Main engine & & 1.90 & 13.1 & & & \\
\hline Main engine & 1 & 1.90 & 13.1 & 0 & 0.46 & 0.15 \\
\hline Propellant management (chemical) & & 86.65 & 20.9 & & & \\
\hline Fuel tanks & 1 & 44.70 & 10.0 & $\begin{array}{l}\text { Cylindrical tank with } \\
\text { spherical domes }\end{array}$ & 49 & ID 45.6 \\
\hline Pressurization system—-tanks, valves, etc & 1 & 25.33 & 10.3 & Spherical & 0 & ID 16.4 \\
\hline Feed system—regulators, valves, etc & 1 & 16.62 & 0.6 & 0 & 0 & 0 \\
\hline RCS hardware & & 3.96 & 163.7 & & & \\
\hline RCS thruster subassembly & 12 & 3.96 & 163.7 & 0 & 0.17 & 0.36 \\
\hline Propellant (chemical) & & 874.91 & 0.0 & & & \\
\hline Main engine propellant & & 865.75 & 0.0 & & & \\
\hline Fuel & & 865.75 & 0.0 & & & \\
\hline Fuel usable & 1 & 785.84 & 0.0 & & & \\
\hline Fuel margin (main and RCS) & 1 & 50.64 & 0.0 & & & \\
\hline Fuel residuals (unused) & 1 & 29.28 & 0.0 & & & \\
\hline Pressurant & & 9.16 & 0.0 & & & \\
\hline Main pressurant & 1 & 9.16 & 0.0 & & & \\
\hline
\end{tabular}




\subsection{Power Subsystem}

\subsubsection{Requirements}

The Electric Power Subsystem (EPS) is responsible for the generation, storage, and distribution of power on the SCHOLR spacecraft. SCHOLR's 3 yr mission requires a reliable power system that would enable continuous operation of the spacecraft subsystems and payloads. During periods of sunlight, the EPS would generate enough power to operate the spacecraft and recharge the spacecraft's batteries. The EPS would store sufficient power to ensure spacecraft survival and allow for reduced payload function during periods without sunlight. At all phases of the mission, power would be distributed along a regulated $28 \mathrm{~V}$ power bus and would be converted to usable voltages at each subsystem.

To size the EPS, a power budget, also known as a Power Equipment List (PEL), and a mission phase document were created to estimate the power consumption by the subsystems during each mission phase, Figures 24(a) and (b). The PEL was the basis for all decisions about the EPS architecture and component sizing calculations and includes a 30 percent growth margin to the final totals in accordance with industry standards (Ref. 36). As seen in Figure 24, the spacecraft consumes $1020 \mathrm{~W}$ while taking scientific measurements over the lunar North Pole and $875 \mathrm{~W}$ while relaying information over the lunar southern hemisphere. During periods of lunar eclipse, reduced payload operations were assumed to reduce energy storage requirements on the EPS.

\subsubsection{Generation}

Photovoltaic arrays were the clear choice of power generation method due to the abundance of solar power available to SCHOLR throughout the $3 \mathrm{yr}$ mission (Ref. 37). Among the choices for photovoltaic arrays were rigid panels, SquareRigger, and the UltraFlex solar array. It was determined that the UltraFlex solar array with triple-junction gallium arsenide cells, shown in Figure 25, was the best choice because it has extremely high power-to-weight ratio (Ref. 38).

The UltraFlex arrays have over $15 \mathrm{yr}$ of development at ATK Space Systems, have flown on the Mars Phoenix Lander, and were selected as the arrays on the New Millennium Program Space Technology 8 mission and the Orion Crew Exploration Vehicle (Refs. 39 and 40). The development of the UltraFlex array for both manned and unmanned missions would enable the SCHOLR spacecraft to reduce risk by
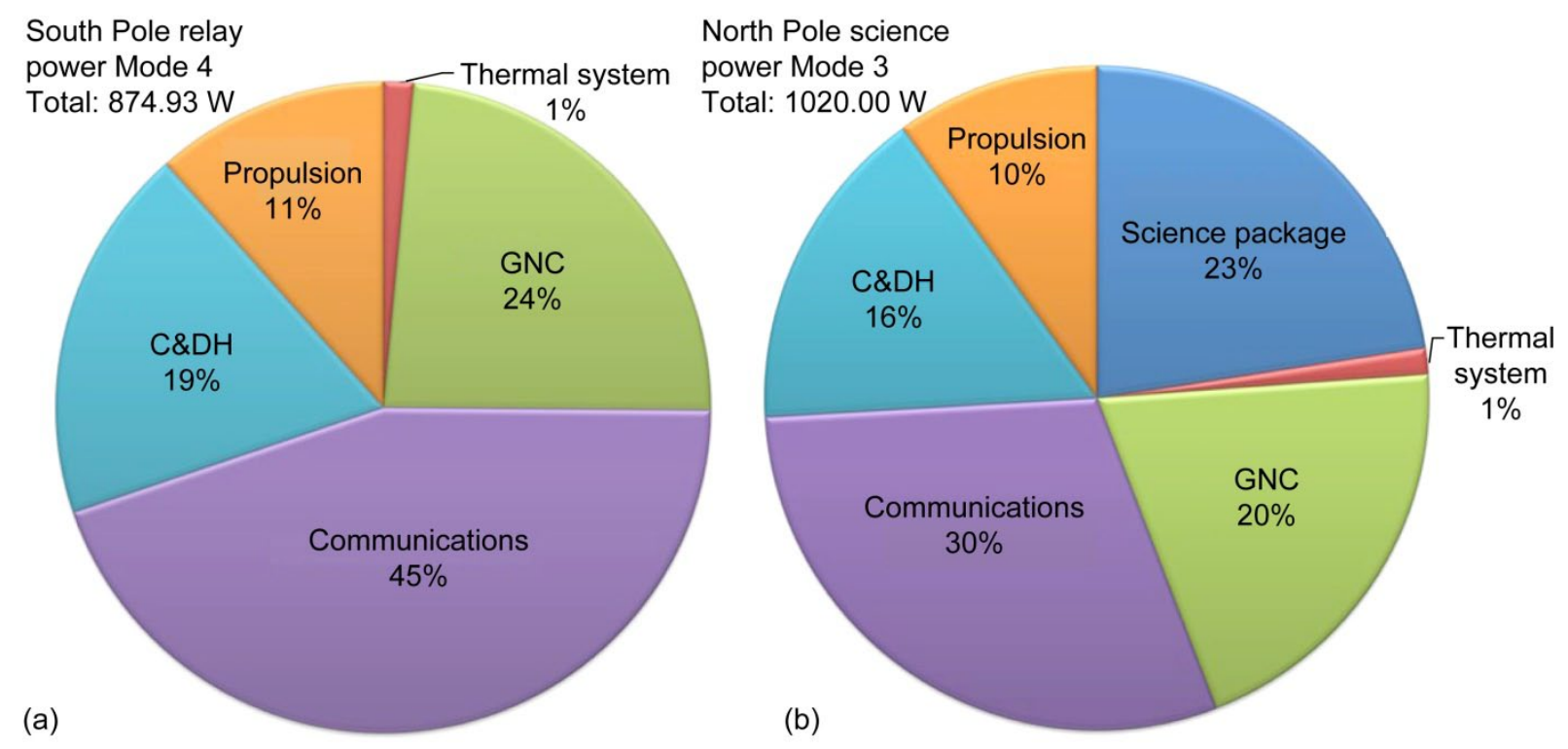

Figure 24.-Power usage. The PEL breaks down the power consumption by subsystem and by mission phase. These charts illustrate the power usage during the science data collection and communications relay phases of the orbit. 


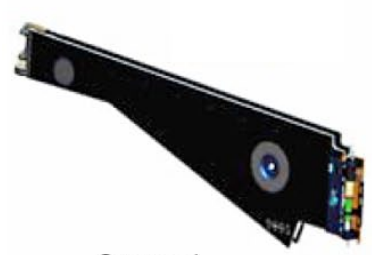

Stowed

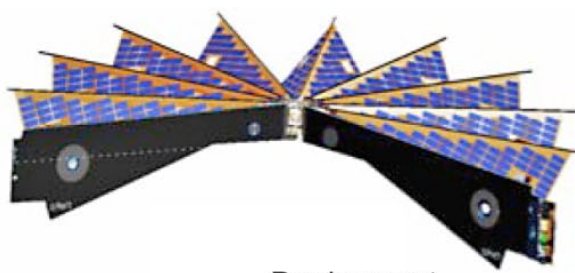

Deployment

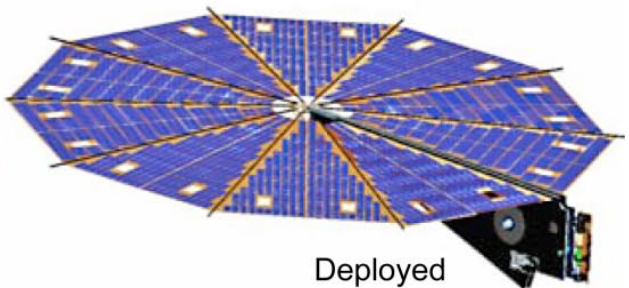

Deployed

Figure 25.-UltraFlex array. The stowed configuration, deployment process, and deployed configuration of the UltraFlex array, developed by ATK Space Systems (Ref. 39).

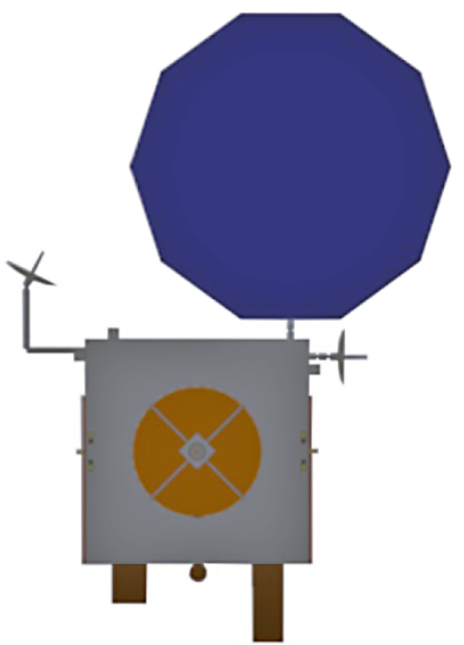

Figure 26.-Solar array mounting. The solar array is mounted on the face opposite the science instruments and uses a single-axis gimbal to track the Sun.

relying on heritage hardware. As seen in Figure 26, the solar array would be mounted on the face opposite the science instruments and would incorporate a single-axis gimbal to track the Sun. After selecting the UltraFlex array, the next step was to determine the appropriate solar array size.

Using traditional power system sizing methodologies (Ref. 41), orbital information, and power information from the PEL, a mathematical model of the EPS was created. To calculate the size of the solar array necessary to generate sufficient power, the model assumed the following:

- State-of-the-art triple-junction GaAs photovoltaic cells achieve 28 percent efficiency at beginning of life (Ref. 38)

- An $8 \mathrm{hr}$ elliptical polar orbit with a worst case eclipse duration of $3 \mathrm{hr}$

- Six percent loss in power supplied due to aging effects of the UltraFlex solar array and 1.5 percent annual degradation due to environmental factors (Ref. 38)

- The power architecture is 85 percent efficient from the solar panels to the instruments during times of insolation and 65 percent efficient during eclipses, when batteries supply power (Ref. 29)

- Less than $15^{\circ}$ of cosine losses due to the inertial pointing of the spacecraft and the Sun-tracking accuracy of the array

Based on these assumptions, it was calculated that a $2 \mathrm{~kW}$ photovoltaic array was able to meet SCHOLR's power generation requirements. The solar array area required for the $3 \mathrm{yr}$ mission is $7.0 \mathrm{~m}^{2}$. To enable a 4 yr extended mission, the solar array area should be enlarged to $7.4 \mathrm{~m}^{2}$ to account for the extra environmental degradation of the array. 


\subsubsection{Storage}

The current best technology for long-term energy storage in space is lithium-ion batteries due to its high specific energy and its ability to withstand the many charge and discharge cycles of a long-term space mission (Ref. 42). Assuming the specific energy of the Li-ion battery pack is $110 \mathrm{Wh} / \mathrm{kg}$, the peak spacecraft power consumption during an eclipse is $875 \mathrm{~W}$, and a worst case eclipse duration of $3 \mathrm{hr}$, it was calculated that a $4.4 \mathrm{~kW}$-hr battery pack would be necessary to operate the spacecraft through periods of lunar eclipse (Ref. 43). This battery pack is oversized so that the battery is never greater than 60 percent discharged, a condition that would damage the battery pack's ability to store charge near the end of the $3 \mathrm{yr}$ mission (Ref. 44). If the power load can be reduced during eclipse cycles, the size of the battery will decrease proportionally.

\subsubsection{Distribution}

The SCHOLR EPS would utilize a direct energy transfer (DET) architecture to transmit power from the solar array to the spacecraft. This calls for a simple and efficient connection between the solar array and the spacecraft's power bus. Excess generated power would be dissipated by a shunt regulator located at the solar array (Ref. 45). The power bus would be regulated near 28 VDC by the battery charge controller and shunt resistors. The battery discharge controller would limit the bus voltage to slightly below $28 \mathrm{~V}$ when the spacecraft is in the lunar shadow. While the spacecraft is in the sunlight, shunt resistors would limit the bus to slightly over $28 \mathrm{~V}$. A $28 \mathrm{~V}$ bus was chosen because flight qualified hardware for this voltage has flown on other missions and is readily available (Ref. 46). Most spacecraft subsystems and components would not link directly to this regulated bus, but would be buffered by DCDC converters that both protect components from voltage variation in the spacecraft power bus and convert the voltage to the appropriate level for that subsystem. This power system architecture, represented in Figure 27, completes the EPS design that would meet the requirements of the SCHOLR mission.

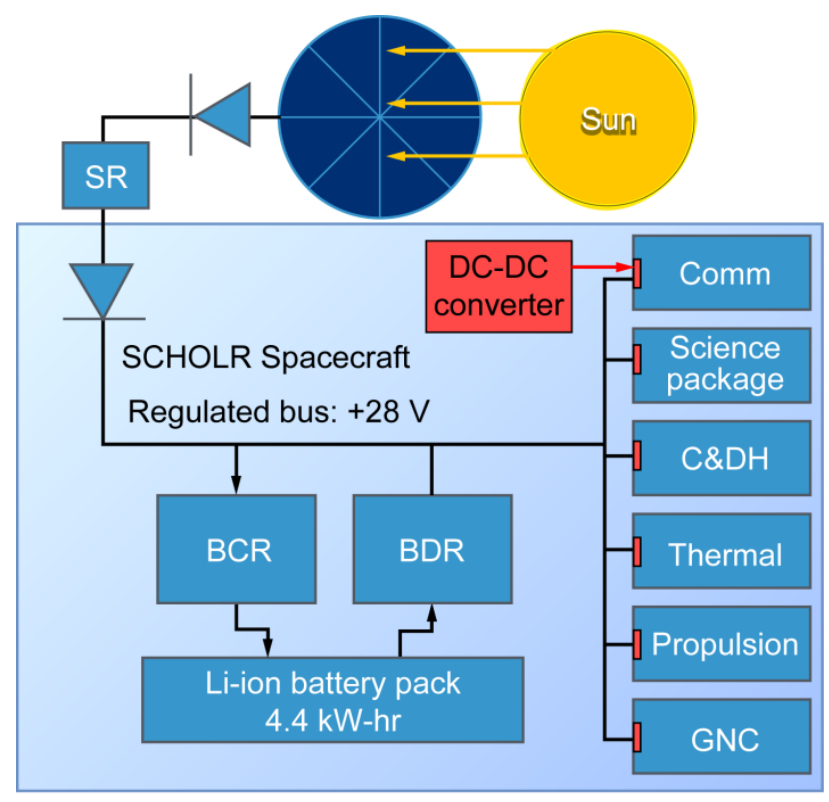

Figure 27.-Power bus architecture. This block diagram represents the direct energy transfer (DET) of power from the solar array to the spacecraft subsystems. The battery charge regulator (BCR), battery discharge regulator (BDR), and shunt regulator (SR) maintain the power bus at a steady +28 VDC. DC-to-DC converters provide the required voltage to each subsystem. 


\subsection{Command and Data Handling Subsystem}

The Command and Data Handling (C\&DH) subsystem of SCHOLR spacecraft is the "brain" responsible for receiving and distributing commands, data packaging and storage, and timekeeping (Ref. 47). The data bus is the "nervous system" responsible for internal spacecraft communications. The command aspect of C\&DH consists of decoding, validating, and executing commands received from Earth. Data handling consists of processing data received from the instruments and payloads, then packaging the data into frames, which can be readily transmitted or stored for future transmission (Ref. 48). The data bus is the interface used to communicate telemetry, commands, and high bandwidth scientific data between C\&DH and other subsystems. The challenge with designing SCHOLR's C\&DH and data bus arises because successful integration of the science and communication missions requires a high performing, reliable system.

\subsubsection{Requirements}

SCHOLR requires an especially capable C\&DH subsystem because the unique mixture of science and communications payloads would result in a high demand for processing power, data storage, and highrate interconnectivity between subsystems. The C\&DH subsystem must integrate the science instrument and the relay communications payloads into one data bus architecture, enabling SCHOLR to perform two functions on one satellite. The single board computer must perform with computational robustness. The data bus must support high data rates ( $>200 \mathrm{mbps}$ ) and low data rates ( $<1 \mathrm{mbps}$ ) between instruments in accordance with their bandwidth requirements. Other requirements are relatively standard across all C\&DH subsystems: it must be space qualified and thermally stable, store science and telemetry data, consume low power, and have a real-time operating system (Ref. 43). From these requirements, the $\mathrm{C} \& \mathrm{DH}$ design process and architecture were conceived.

\subsubsection{Design Process}

A preliminary C\&DH design was created based on the designs of previous missions, especially the LRO and Lunar Crater Observation and Sensing Satellite (Ref. 49). From this starting point, a core set of technologies was evaluated and trade studies were performed to determine where state-of-the-art advances could improve upon the LRO data bus design. Specifications such as mass, cost, power, and performance were analyzed, with space qualification being an absolute requirement. The most attention was given to trades for data bus architecture and technology as shown in Table 11.

TABLE 11.-TRADE STUDY FOR SYSTEM ARCHITECTURE (REF. 50)

\begin{tabular}{|l|l|l|l|}
\hline $\begin{array}{c}\text { Architecture } \\
\text { type }\end{array}$ & \multicolumn{1}{|c|}{ Characteristics } & \multicolumn{1}{|c|}{ Pros } & \multicolumn{1}{c|}{ Cons } \\
\hline Centralized & $\begin{array}{l}\text { Central computer is connected to } \\
\text { every subsystem }\end{array}$ & $\begin{array}{l}\text { Failure of one system does not } \\
\text { affect other subsystems }\end{array}$ & $\begin{array}{l}\text { Difficult to add additional } \\
\text { subsystems to a design }\end{array}$ \\
\hline Ring & Subsystems connected in series & Easy addition of new subsystems & $\begin{array}{l}\text { Failure of one system may lead to } \\
\text { failure of entire spacecraft }\end{array}$ \\
\hline Federated bus & $\begin{array}{l}\text { Subsystems connected to each } \\
\text { other as well as central computer }\end{array}$ & $\begin{array}{l}\text { Direct data paths between all } \\
\text { subsystems, easy to troubleshoot }\end{array}$ & $\begin{array}{l}\text { Requires subsystems to have } \\
\text { specific interfaces to communicate } \\
\text { via a common bus }\end{array}$ \\
\hline Distributed bus & Federated bus, multiple processors & $\begin{array}{l}\text { Allows for simultaneous } \\
\text { command execution }\end{array}$ & $\begin{array}{l}\text { Difficult to test, more complex } \\
\text { design }\end{array}$ \\
\hline
\end{tabular}

\subsubsection{Final C\&DH Architecture}

The final C\&DH architecture is based on the centralized concept and is shown in Figure 28. There are separate controllers for the environmental control system, housekeeping, Ka-band, S-band, and Optical communications alongside the single board computer and solid-state drive. Each of these components takes the form of a PCI card inserted into the backplane of a rigid and space qualified enclosure responsible for protection and thermal management of the electronics (Ref. 49). The backplane acts as an 
interface for each of the components through which power is distributed and communications between cards is transmitted. Central to this configuration is the Single Board Computer, which is based off of a RAD750 PowerPC microprocessor from BAE Systems. The RAD750 was selected because it has a long flight history, outperforms the similarly priced options (Ref. 51), and is far less expensive than other processors (Ref. 52 and 53). Tests performed with LRO’s C\&DH system using the RAD750 provide assurance that the RAD750 is capable of handling the simultaneous high bandwidth data transmission, normal housekeeping operations, and collecting and processing science data loads that the SCHOLR spacecraft would encounter (Ref. 49). Since LRO was developed, the RAD750 processor performance has increased to $200 \mathrm{MHz}$, SRAM capacity has increased, and SpaceWire has reached the next level of integration with the processor (Ref. 54). These advancements will enhance spacecraft performance. For redundancy, each critical component will have a cold backup that can take over upon a hardware failure.

The centralized architecture of the data bus incorporates a central processing unit that is connected to every subsystem through a dedicated link. This limits the ability of an instrument failure on one link to affect instruments other communications links (Ref. 50). For high data rate instruments, redundant SpaceWire links connect to two centralized routers that will each provide communications at up to 400 mbps (Ref. 55). Low data rate instruments will utilize redundant MIL-STD-1553 links for communications up to 1 mbps (Ref. 56). This architecture enables the RAD750 computer to process data from both the science and communications payloads, as well as control the other subsystems and monitoring their state.

\subsubsection{Atomic Clock}

It was determined that SCHOLR would carry a single atomic clock for the purpose of knowing precise spacecraft location. While this atomic clock may be used to study the Moon's gravitational field or provide precise metadata for measurements taken by the science payload, the primary purpose is to enable the extremely accurate pointing desired by the optical communication transmitters and receivers. As optical communication is only a technology demonstration, there would not be a second atomic clock for single string redundancy.

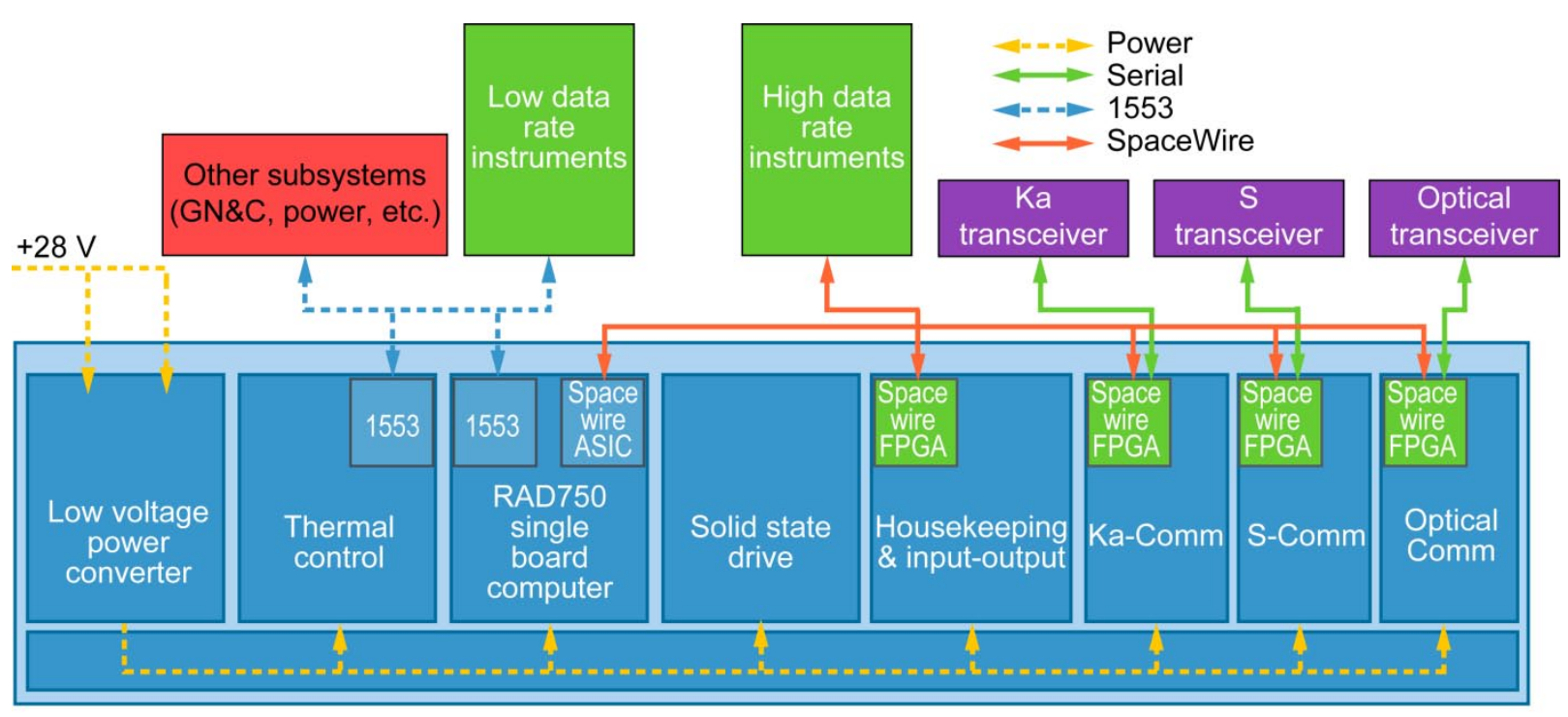

Figure 28.-Final C\&DH architecture. 


\subsection{Communications Subsystem}

SCHOLR's communications subsystem supports both relay and science data from the two payloads as well as its own TT\&C. DTE communications is necessary to send lunar surface data received by the LCP back to Earth through a bent pipe relay or by using store and forward methods. When orbiting the South Pole of the Moon, SCHOLR would serve as a relay for any lunar surface assets and communicate back to Earth if SCHOLR is in line of sight with Earth's ground stations. If there is no line of sight, SCHOLR would store the data and forward it when access becomes available. When supporting North Pole science missions, data collected by SCHOLR would be transmitted back to Earth at a high data rate. The satellite requires a DTE link to enable SCHOLR to serve both its science and communications relay objectives while maintaining communications with Earth ground stations when in line of sight.

\subsubsection{Requirements}

To satisfy mission and science requirements, the communications subsystem and mission node communication links must maintain the following requirements:

- Provide a communications relay capability for times when lunar surface assets have poor or nonexistent line-of-sight with Earth

- Provide a high data rate link at $200 \mathrm{Mbps}$ in Ka-band to transmit all science and relay data

- $\quad$ Provide a 4 Mbps and 16 Kbps S-band link to Earth to ensure that TT\&C functions are met

- $\quad$ BER of no greater than $10^{-8}$ and a link margin of no less than $3 \mathrm{~dB}$ to ensure link closure (Ref. 6)

- Support a technology demonstration payload to help develop optical communications in space

The communication links required are illustrated in Figure 29.

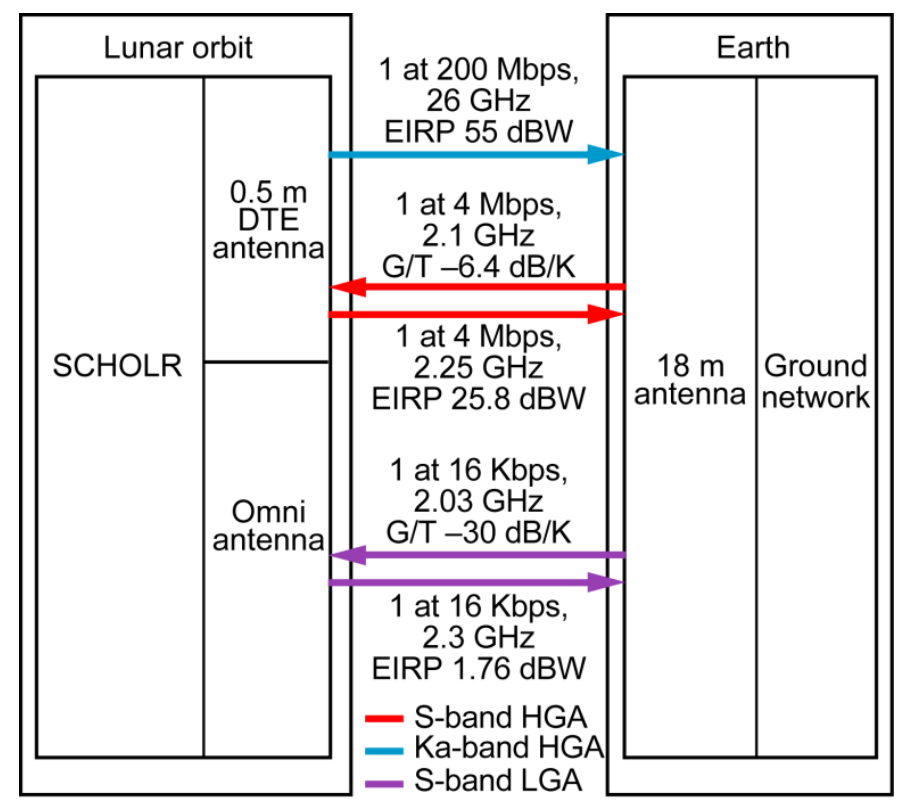

Figure 29.-Data rate overview. SCHOLR's DTE data rates and frequencies. 


\subsubsection{Assumptions}

The design of SCHOLR's DTE communications was sized to the specifications of an $18 \mathrm{~m}$ diameter antenna located at the White Sands Complex in New Mexico. This ground antenna was previously used by LRO and has been used in conceptual lunar relay studies (Ref. 18). The $18 \mathrm{~m}$ ground antenna was duplicated and placed at each DSN site for link analysis. SCHOLR's communications system assumed this ground network of $18 \mathrm{~m}$ dishes would be constructed in the future at DSN sites.

The worst case scenario for signals was accounted for during the link analysis. The impact of atmospheric absorption was considered, which would provide the link with a worst case scenario to allow a robust link analysis. The parabolic antenna efficiency was assumed to be 55 percent (Ref. 21). After these initial assumptions were made, an initial communications system was developed, including antenna size, frequency, and placement on the craft.

\subsubsection{Design}

Design features that had to be initially considered were the use of dual feed antennas and overall pointing of the craft while in lunar orbit. SCHOLR's pointing requirements stem from the science payload, radiators, as well as communication needs. The antennas must be pointing in the correct direction to reduce the use of booms and gimbals and optimize access time to Earth.

To meet the high data rates required of the DTE link, the antenna design includes a dual feed parabolic high gain antenna (HGA) capable of Ka-band and S-band frequencies. Use of the dual feed antenna reduces the number of parabolic antennas down to two; a DTE and LCP antenna. The Ka-band frequency was determined to be $26 \mathrm{GHz}$ due to the capabilities of the $18 \mathrm{~m}$ dish at White Sands (Ref. 18). The frequency and link nodes are illustrated in Figure 29.

A range of antenna diameters from 0.2 to $1 \mathrm{~m}$ was evaluated to ensure gain was high enough to meet the link margin and BER requirements. The analysis indicated that a $0.5 \mathrm{~m}$ diameter antenna would be required to receive and transmit at $200 \mathrm{Mbps}$ in Ka-band. Accounting for the assumed antenna efficiency, the gain produced by this frequency and diameter is $40.08 \mathrm{~dB}$ (Ref. 57). The parameter used for sizing the Ka-band DTE link was EIRP, which was calculated to be $55 \mathrm{dBW}$ or using approximately $30 \mathrm{~W}$ of transmit power with the calculated gain.

The high efficiency K-band traveling-wave tube amplifier (TWTA), first used on the LRO (Ref. 58), was used to reduce transmit power. The modulation used for all links was QPSK with LDPC coding, which provides a coding gain that improves the BER (Ref. 20). The physical aspects of each major component of the subsystem are presented in the block diagram in Figure 30.

The medium data rates for the DTE link were determined to require S-band, and the chosen rates for transmitting and receiving are illustrated in Figure 29. These data rates are chosen based on the S-band capabilities of the $18 \mathrm{~m}$ White Sands antenna (Ref. 59). Using the $0.5 \mathrm{~m}$ antenna and ensuring that transmit power is minimized to remain within the budgeted power, a transmit power of $5 \mathrm{~W}$ was assumed to achieve a gain of $18.8 \mathrm{~dB}$. $5 \mathrm{~W}$ of power is the minimum power that can be used to provide enough access time to allow all data to be sent back to Earth and still meet link margin and BER requirements. The standard system noise temperature that a satellite receives at is $290 \mathrm{~K}$ for the uplink in S-band (Ref. 60). Using this temperature as the lower limit, G/T can be determined for the link. A G/T of $-30 \mathrm{~dB} / \mathrm{K}$ maintains the desired temperature and allows for a link with proper gain in order to maintain link margin and BER requirements.

To provide a backup communication capability, a very low data rate link was added with a rate of $16 \mathrm{Kbps}$ as illustrated in Figure 29. Using four omni-directional antennas, similar to the ones in Table 12, communications can be established in the event that failures occur with the HGA. During launch and at the beginning of the trans-lunar injection burn, when the HGA is stowed away, the omni-directional antennas would be used for primary communications to ensure the life systems of the satellite are working and still functional. 


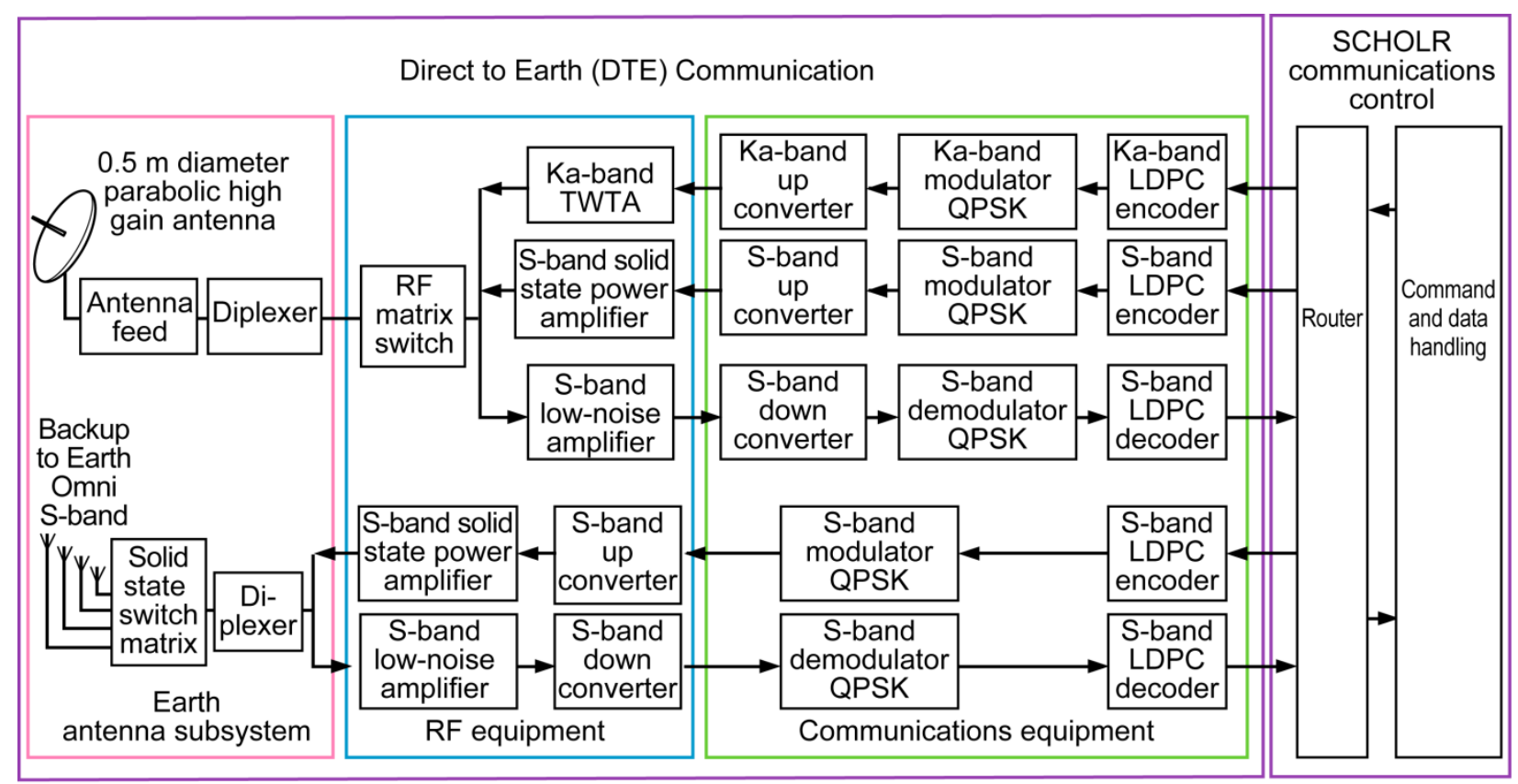

Figure 30.-DTE block diagram. Major components of physical DTE communications subsystem.

TABLE 12.-DTE COMMUNICATIONS MAIN COMPONENTS

\begin{tabular}{|l|l|}
\hline Parabolic HGA & $\bullet$ 0.5 m diameter \\
& - Dual-feed \\
& - Pasports Ka and S-band \\
\hline $\begin{array}{l}\text { Omni-directional } \\
\text { antennas }\end{array}$ & $\bullet$ Four antennas spaced $90^{\circ}$ apart to provide $360^{\circ}$ coverage \\
& - Supports S-band \\
\hline TWTA & Passive Power \\
\hline
\end{tabular}

\subsection{Summary}

The SCHOLR mission was designed to close gaps in the current understanding of the Moon by collecting new lunar science data and providing a communications relay service to lunar surface assets on the southern hemisphere. The SCHOLR mission and subsystems have been fully explored and defined to the detail of a conceptual design. This design includes an orbit optimized to perform both lunar relay functions as well as collect important science data. A science payload was selected to unlock the mysteries of water at the lunar poles and a lunar communications payload was designed to enable lunar surface exploration on the southern hemisphere. An optical communications technology demonstration was also incorporated into the design to advance in-space communications capabilities. For further project development, targets of opportunity will be sought from NASA and other agencies. NASA's Space Communication and Navigation program is closely reviewing the project results and considering the potential continuation of design to fulfill the lunar mission communication requirements. 


\section{Appendix A.-Nomenclature}

\begin{tabular}{|c|c|}
\hline AIRS & Active Infrared Spectrometer \\
\hline BER & bit error rate \\
\hline $\mathrm{C} \& \mathrm{DH}$ & Command and Data Handling \\
\hline COMPASS & Collaborative Modeling for Parametric Assessment of Space Systems \\
\hline COTS & commercial off the shelf \\
\hline DC & direct current \\
\hline DET & Direct Energy Transfer \\
\hline DSN & Deep Space Network \\
\hline DTE & direct to Earth \\
\hline $\mathrm{E}_{\mathrm{b}} / \mathrm{N}_{0}$ & signal to noise $(\mathrm{dB} / \mathrm{W})$ \\
\hline ECS & Environmental Control System \\
\hline EIRP & Equivalent Isotropic Radiated Power \\
\hline EPS & Electric Power Subsystem \\
\hline FOV & field of view \\
\hline GN\&C & Guidance, Navigation, and Control \\
\hline GRS & Gamma Ray Spectrometer \\
\hline $\mathrm{G} / \mathrm{T}$ & gain over system noise temperature $(\mathrm{dB} / \mathrm{K})$ \\
\hline HGA & high gain antenna \\
\hline JPL & NASA Jet Propulsion Laboratory \\
\hline K & Kelvin \\
\hline Kbps & Kilobits per second \\
\hline KREEP & Potassium, Rare Earth Elements, Phosphorous \\
\hline LADEE & Lunar Atmosphere and Dust Environment Explorer \\
\hline LCP & Lunar Communications Payload \\
\hline LDPC & low-density parity-check \\
\hline LOLA & Lunar Orbiter Laser Altimeter \\
\hline LRO & Lunar Reconnaissance Orbiter \\
\hline LROC & Lunar Reconnaissance Orbiter Camera \\
\hline Mbps & Megabits per second \\
\hline MEL & Master Equipment List \\
\hline MOC & Mission Operations Center \\
\hline NASA & National Aeronautics and Space Administration \\
\hline PCM & Phase Change Material \\
\hline PEL & Power Equipment List \\
\hline QPSK & quadrature phase shift keying \\
\hline $\mathrm{RF}$ & radio frequency \\
\hline RHCP & Right Hand Circular Polarization \\
\hline SCaN & Space Communications and Navigation \\
\hline SCEM & Scientific Context for Exploration of the Moon \\
\hline SCHOLR & Science Hybrid Orbiter and Lunar Relay \\
\hline
\end{tabular}


SIP Science Instrument Payload

SOAP Satellite Orbit Analysis Program

STK Satellite Tool Kit

TRL Technology Readiness Level

TT\&C Telemetry, Tracking and Command

TWTA Traveling Wave Tube Amplifier

$\mathrm{W}_{\mathrm{t}} \quad$ Watts thermal 


\section{References}

1. Space Studies Board, Scientific Context for Exploration of the Moon, Washington D.C.: National Academies Press.

2. Dori, Dov, Object-Process Methodology: A Holistic Systems Paradigm, Springer-Verlag, Berlin, 2002.

3. Canadian Space Agency, “CASSIOPE’s ePOP probe will study upper atmosphere,” Canadian Space Agency Website, URL: http://www.asc-csa.gc.ca/eng/satellites/cassiope.asp [cited Aug. 3, 2010].

4. Yau, A.W., and James, H.G., "CASSIOPE Enhanced Polar Outflow Probe (e-POP) Small Satellite Mission: Space Plasma Observations and International Collaboration,” Future Perspectives of Space Plasma and Particle Instrumentation and International Collaborations, American Institute of Physics, 2009.

5. NASA Jet Propulsion Laboratory, “Mars Reconnaissance Orbiter: Electra,” NASA Mars Reconnaissance Orbiter, URL: http://marsprogram.jpl.nasa.gov/mro/mission/instruments/electra/ [cited Aug. 9, 2010].

6. Oleson, Steven R., Bhasin, Kul B., McGuire, Melissa L., and Knoblock, Eric J., “Advanced Communications and Navigation Satellite Conceptual Design for Lunar Network-Centric Operations,” AIAA-2009-6719, AIAA SPACE 2009 Conference and Exposition, Pasadena, CA, Sep. 14-17, 2009.

7. Hamera, Kathryn, Mosher, Todd, Gefreh, Mark, Paul, Robert, Slavkin, Leon, and Trojan, Joseph. “An Evolvable Lunar Communication and Navigation Constellation Concept," IEEE Aerospace Conference, Big Sky, MT, Mar. 1-8, 2008.

8. NASA Science Mission Directorate, “LADEE,” NASA Science Missions, URL:http://science.nasa.gov/missions/ladee [cited Jul. 4, 2010].

9. Department of Defense, "DoDAF Architecture Framework Version 2.0," Department of Defense, URL: http://cio-nii.defense.gov/sites/dodaf20/ [cited Aug. 9, 2010]

10. Ackerman, Evan, “Scarab Lunar Prospector to be Tested in Hawaii,” Bot Junkie, URL: http://www.botjunkie.com/2008/10/15/scarab-lunar-prospector-to-be-tested-in-hawaii/ [cited Aug. 1, 2010].

11. Pieters, C.M., et al., "Character and Spatial Distribution of $\mathrm{OH} / \mathrm{H}_{2} \mathrm{O}$ on the Surface of the Moon as Seen by M3 on Chandrayaan-1,” AAAS Science [online database], Vol. 326, No. 5952, pp. 568572, URL: http://www.sciencemag.org/cgi/content/abstract/1178658 [cited 29 July 2010], 2009.

12. Yamashita, Naoyuki, and et al, "Germanium Gamma-Ray Spectrometer on SELENE (KAGUYA)," Journal of Physical Society of Japan, Vol. 78, Supplement A, 2009, pp. 153-156.

13. Ono, Takayuki, and Oya, Hiroshi, "Lunar Radar Sounder (LRS) experiment on-board the SELENE spacecraft,” Earth Planets Space, Vol. 52, 2000, pp. 629-637.

14. Davarian, F., Farr, W., Hemmati, H., and Piazzolla, S., "Optical Communications From Planetary Distances,” AIAA SpaceOps 2008 Conference, AIAA-2008-3405, Heidelberg, Germany, May 1216, 2008.

15. Boroson, D.M., Scozzafava, J.J., Robinson, B.S., and Shaw, H., "The Lunar Laser Communications Demonstration (LLCD),” Third IEEE International Conference on Space Mission Challenges for Information Technology, Pasadena, CA, 19-23 July, 2009.

16. Houghton, Martin B., Tooley, Craig R., and Saylor, Richard S. Jr., "Mission Design and Operations Considerations for NASA’s Lunar Reconnaissance Orbiter,” NASA IAC-07-C1.7.06, 2006.

17. Bhasin, Kul B., Warner, Joseph D., and Anderson, Lynn M., "Lunar Communications Terminals for NASA Exploration Missions: Needs, Operations, Concepts and Architectures,” 26th ICSSC, AIAA2008-5479, San Diego, CA, 2008.

18. Schier, James, et al., "NASA's Lunar Communication and Navigation Architecture,” AIAA SpaceOps 2008 Conference, AIAA-2008-3589, Heidelberg, Germany, 2008.

19. STK, Satellite Tool Kit, Software Package. Ver. 9.2.0, Analytical Graphics, Inc., 1989-2010, URL: http://www.stk.com/ [cited Jul. 29, 2010]. 
20. Andreadou, Nikoleta, Pavlidou, Fotini-Niovi, Papaharalabos, Stylianos, and Mathiopoulos, P. Takis, "Quasi-Cyclic Low-Density Parity-Check (QC-LDPC) Codes for Deep Space and High Data Rate Applications,” IEEE Xplore[online database], URL: http://ieeexplore.ieee.org/stamp /stamp.jsp?arnumber=05286377 [cited Jul. 29, 2010].

21. Wertz, James R, and Larson, Wiley J. (eds.), “Communications Architecture,” Space Mission Analysis and Design, 3rd ed., Microcosm Press, El Segundo, CA, 1999, Ch. 13.

22. Folta, David, and Quinn, David, "Lunar Frozen Orbits," AIAA/AAS Astrodynamics Specialist Conference and Exhibit, AIAA 2006-6749, Keystone, CO, Aug. 21-24, 2006.

23. SOAP, Satellite Orbit Analysis Program, Software Package, Ver. 13.4.2, The Aerospace Corporation, El Segundo, CA, 2009.

24. Bate, R.R., Mueller, D.D., and White, J.E., Fundamentals of Astrodynamics, Dover Publications, New York, NY, 1971, Chs. 1, 3, 4, and 7.

25. Sarafin, Thomas P. (ed.), Spacecraft Structures and Mechanisms: From Concept to Launch, Springer, New York, NY, 1995, Part V. Design.

26. ABLE Engineering, "Boom Information,” ABLE Booms, URL: http://www.aec-able.com/Booms/ Resources/Boom\%20Information.pdf [cited Jul. 29, 2010].

27. Griffin, Michael D., and French, James R., Space Vehicle Design, 2nd ed., AIAA, Reston, VA, 2004.

28. Solid Works 2010, Software Package, Dassault Systèmes SolidWorks Corp., Concord, MA, 2010

29. Wertz, James R, and Larson, Wiley J. (eds.), Space Mission Analysis and Design, 3rd ed., Microcosm Press, El Segundo, CA, 1999, p. 413.

30. Wertz, James R, and Larson, Wiley J. (eds.), Space Mission Analysis and Design, 3rd ed., Microcosm Press, El Segundo, CA, 1999, p. 553.

31. Wertz, James R, and Larson, Wiley J. (eds.), Space Mission Analysis and Design, 3rd ed., Microcosm Press, El Segundo, CA, 1999, p. 439.

32. Wertz, James R, and Larson, Wiley J. (eds.), Space Mission Analysis and Design, 3rd ed., Microcosm Press, El Segundo, CA, 1999, p. 359.

33. Wertz, James R, and Larson, Wiley J. (eds.), Space Mission Analysis and Design, 3rd ed., Microcosm Press, El Segundo, CA, 1999, p. 368.

34. Wertz, James R, and Larson, Wiley J. (eds.), Space Mission Analysis and Design, 3rd ed., Microcosm Press, El Segundo, CA, 1999, p. 371.

35. Neff, K., King, P., Anflo, K., and Möllerberg, R., "High Performance Green Propellant for Satellite Applications," 45th AIAA/ASME/SAE/ASEE Joint Propulsion Conference \& Exhibit, AIAA 20094878, Denver, CO, Aug. 2-5, 2009.

36. AIAA, AIAA Mass Properties Control for Space Systems, AIAA S-120-2006, 2006.

37. Wertz, James R, and Larson, Wiley J. (eds.), “Communications Architecture,” Space Mission Analysis and Design, 3rd ed., Microcosm Press, El Segundo, CA, 1999, p. 411.

38. Murfy, D. M., Eskenazi, M. I., White, S. F., and Spence, B. R., Thin-Film and Crystalline Solar Cell Array System Performance Comparisons, Goleta, CA: AEC-Able (ABLE) Engineering.

39. Jones, A., White, S., and Harvy, J, "A High Specific Power Solar Array for Low to Mid-Power Spacecraft,” Goleta, CA: AEC-Able Engineering Company, Inc., 1994.

40. Spence, B., White, S., Wilder, N., Gregory, T., Douglas, M., and Takeda, R, "Next Generation UltraFlex Solar Array for NASA's New Millennium Program Space Technology 8,” Goleta, CA: AEC-Able Engineering, 2005.

41. Wertz, James R, and Larson, Wiley J. (eds.), Space Mission Analysis and Design, 3rd ed., Microcosm Press, El Segundo, CA, 1999, pp. 411-418.

42. Ley, W., Wittmann, K., and Hallmann, W, Handbook of Space Technology, John Wiley \& Sons, Ltd., Munich, Germany, 2009, p. 262.

43. Ley, W., Wittmann, K., and Hallmann, W, Handbook of Space Technology, John Wiley \& Sons, Ltd., Munich, Germany, 2009.

44. Ley, W., Wittmann, K., and Hallmann, W, Handbook of Space Technology, John Wiley \& Sons, Ltd., Munich, Germany, 2009, p. 258. 
45. Wertz, James R, and Larson, Wiley J. (eds.), Space Mission Analysis and Design, 3rd ed., Microcosm Press, El Segundo, CA, 1999, p. 426.

46. Wertz, James R, and Larson, Wiley J. (eds.), Space Mission Analysis and Design, 3rd ed., Microcosm Press, El Segundo, CA, 1999, p. 423.

47. Cutler, J., "Command and Data Handling (C\&DH)," [Powerpoint], Stanford University, Palo Alto, CA, 2006.

48. Wertz, James R, and Larson, Wiley J. (eds.), Space Mission Analysis and Design, 3rd ed., Microcosm Press, El Segundo, CA, 1999, p. 397.

49. Nguyen, Q., Yuknis, W., Pursley, S., Haghani, N., Albaijes, D., and Haddad, O., “A High Performance Command and Data Handling System for NASA's Lunar Reconnaissance Orbiter," AIAA SPACE 2008 Conference and Exposition, AIAA-2008-7926, San Diego, CA, Sep. 9-11, 2008.

50. Akinli, C., Gamache, M., Rose, M., Rost, A., Sales, J., and Tang, J., “Telemetry, Tracking, Communications, Command and Data Handling,” Virginia Polytechnic Institute and State University, Blacksburg, VA, 2004.

51. Honeywell International Inc., RHPPC Single Board Computer [data sheet], URL: http://www51.honeywell.com/aero/common/documents/myaerospacecatalog-documents/Spacedocuments/RHPPC.pdf [cited Jul. 29, 2010], Clear Water, FL, 2006.

52. BAE Systems, RAD750 radiation-hardened PowerPC microprocessor [data sheet], URL: http://www.baesystems.com/BAEProd/groups/public/@businesses/@eandis/documents/bae_publicat ion/bae_pdf_eis_rad750_pwr_pc_mp.pdf [cited 29 July 2010], Manassas, VA, 2008.

53. Maxwell Technologies, SCS750 Single Board Computer for Space [data sheet], URL:http://www.maxwell.com/pdf/me/product_datasheets/sbc/scs750_rev6.pdf [cited Jul. 29, 2010], San Diego, CA, 2006.

54. Berger, R., Dennis, A., Eckhardt, D., Miller, S., Robertson, J., Saridakis, D., et al., "RAD750 SpaceWire-Enabled Flight Computer for Lunar Reconnaissance Orbiter,” BAE Systems, Manassas, VA, 2007.

55. Parkes, S., and Armbruster, P., "SpaceWire: Spacecraft Onboard Data-Handling Network," University of Dundee, Scotland, UK, 2009.

56. Axon' Cable, MIL-STD-1553 Databus Harnesses [data sheet], URL: www.axon-cable.com/pdf/ space\%20data\%20bus\%20harnesses.pdf [cited 29 July 2010], Montmirai, Paris, 2005.

57. Wertz, James R, and Larson, Wiley J. (eds.), Space Mission Analysis and Design, 3rd ed., Microcosm Press, El Segundo, CA, 1999, p. 571.

58. Simons, Rainee N., et al., "High-Efficiency K-band Space Traveling-Wave Tube Amplifier for Near-Earth High Data Rate Communications,” NASA/TM-2010-216262, NASA, Mar. 2010.

59. NASA Goddard Space Flight Center, Near Earth Network (NEN) Users' Guide, Revision 1, 2010.

60. Wertz, James R, and Larson, Wiley J. (eds.), Space Mission Analysis and Design, 3rd ed., Microcosm Press, El Segundo, CA, 1999, p. 558. 


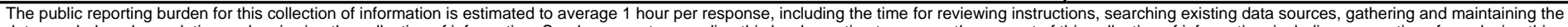

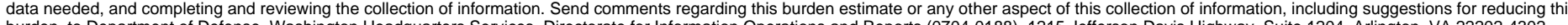

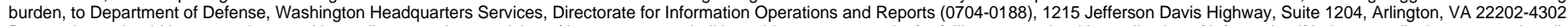

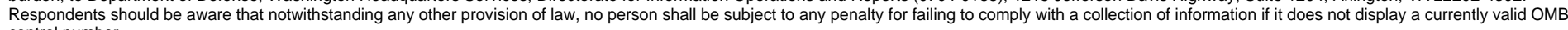

control number.
PLEASE DO NOT RETURN YOUR FORM TO THE ABOVE ADDRESS

\begin{tabular}{l|l|l}
\hline $\begin{array}{l}\text { 1. REPORT DATE (DD-MM-YYYY) } \\
01-07-2011\end{array}$ & $\begin{array}{l}\text { 2. REPORT TYPE } \\
\text { Technical Memorandum }\end{array}$ & 3. DATES COVERED (FrOm - To)
\end{tabular}

4. TITLE AND SUBTITLE

Technical Memorandum

SCience Hybrid Orbiter and Lunar Relay (SCHOLR) Architecture and Design

5a. CONTRACT NUMBER

5b. GRANT NUMBER

5c. PROGRAM ELEMENT NUMBER

6. AUTHOR(S)

Trase, Kathryn, K.; Barch, Rachel, A.; Chaney, Ryan, E.; Coulter, Rachel, A.; Gao, Hui; Huynh, David, P.; Iaconis, Nicholas, A.; MacMillan, Todd, S.; Pitner, Gregory, M.; Schwab, Devin, $\mathrm{T}$.

\section{5d. PROJECT NUMBER}

5e. TASK NUMBER

5f. WORK UNIT NUMBER

WBS 439432.07.01.15.07.01

7. PERFORMING ORGANIZATION NAME(S) AND ADDRESS(ES)

National Aeronautics and Space Administration

John H. Glenn Research Center at Lewis Field

8. PERFORMING ORGANIZATION REPORT NUMBER

E-17473

Cleveland, Ohio 44135-3191

\section{SPONSORING/MONITORING AGENCY NAME(S) AND ADDRESS(ES)}

National Aeronautics and Space Administration

Washington, DC 20546-0001

\section{SPONSORING/MONITOR'S ACRONYM(S) \\ NASA}

11. SPONSORING/MONITORING REPORT NUMBER

NASA/TM-2011-216894

\section{DISTRIBUTIONIAVAILABILITY STATEMENT}

Unclassified-Unlimited

Subject Categories: 18 and 91

Available electronically at http://gltrs.grc.nasa.gov

This publication is available from the NASA Center for AeroSpace Information, 443-757-5802

\section{SUPPLEMENTARY NOTES}

\section{ABSTRACT}

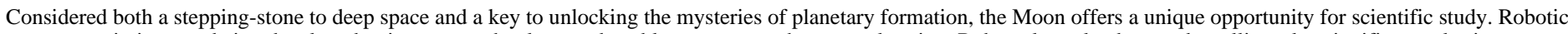
precursor missions are being developed to improve technology and enable new approaches to exploration. Robots, lunar landers, and satellites play significant roles in

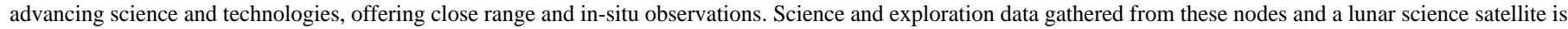

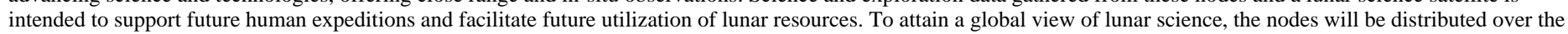

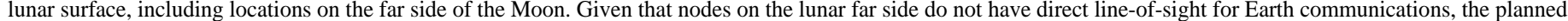

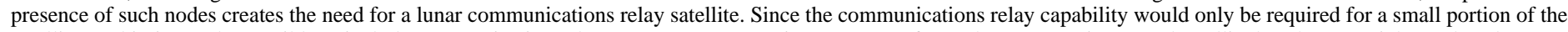

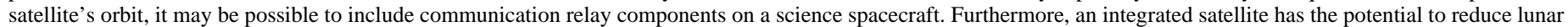

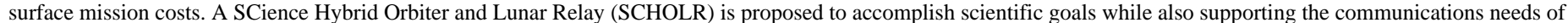

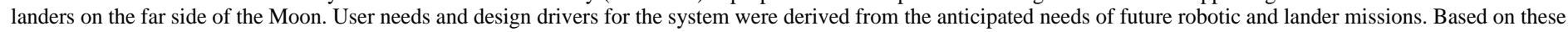

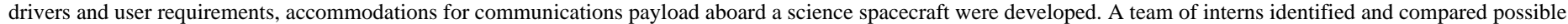

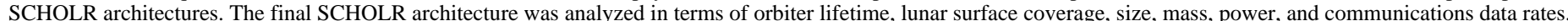

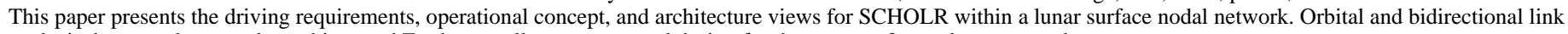
analysis, between lunar nodes, orbiter, and Earth, as well as a conceptual design for the spacecraft are also presented.

\section{SUBJECT TERMS}

Lunar satellites; Lunar communication; Moon; Relay; Lunar exploration

\begin{tabular}{|l|l|l|l|l|l|}
\hline \multicolumn{2}{|l|}{ 16. SECURITY CLASSIFICATION OF: } & $\begin{array}{l}\text { 17. LIMITATION OF } \\
\text { ABSTRACT }\end{array}$ & $\begin{array}{l}\text { 18. NUMBER } \\
\text { OF } \\
\text { PAGES }\end{array}$ & $\begin{array}{l}\text { 19a. NAME OF RESPONSIBLE PERSON } \\
\text { STI Help Desk (email:help@sti.nasa.gov) }\end{array}$ \\
\cline { 1 - 2 } $\begin{array}{l}\text { a. REPORT } \\
\text { U }\end{array}$ & $\begin{array}{l}\text { b. ABSTRACT } \\
\text { U }\end{array}$ & $\begin{array}{l}\text { c. THIS } \\
\text { PAGE } \\
\text { U }\end{array}$ & UU & 45 & $\begin{array}{l}\text { 19b. TELEPHONE NUMBER (include area code) } \\
\text { 4t43-757-5802 }\end{array}$ \\
\hline
\end{tabular}



